Technological University Dublin

ARROW@TU Dublin

\title{
Comparing Grounded Theory and Phenomenology as Methods to Understand Lived Experience of Engineering Educators Implementing Problem-based Learning
}

\author{
Shannon Chance \\ Technological University Dublin, shannon.chance@tudublin.ie \\ Gavin Duffy \\ Technological University Dublin, gavin.duffy@tudublin.ie \\ Brian Bowe \\ Technological University Dublin, Brian.Bowe@TUDublin.ie
}

Follow this and additional works at: https://arrow.tudublin.ie/engscheleart2

Part of the Educational Methods Commons

\section{Recommended Citation}

Chance, S., Duffy, G. \& Bowe, B. (2019). Comparing grounded theory and phenomenology as methods to understand lived experience of engineering educators implementing problem-based learning. European Journal of Engineering Education, doi:10.1080/03043797.2019.1607826

This Article is brought to you for free and open access by the School of Electrical and Electronic Engineering at ARROW@TU Dublin. It has been accepted for inclusion in Articles by an authorized administrator of ARROW@TU Dublin. For more information, please contact arrow.admin@tudublin.ie, aisling.coyne@tudublin.ie, gerard.connolly@tudublin.ie.

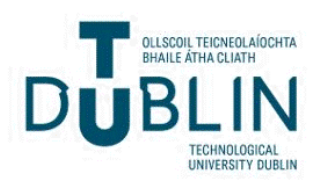




\title{
Comparing grounded theory and phenomenology as methods to understand lived experience of engineering educators implementing Problem-Based Learning
}

\author{
Shannon Chance ${ }^{1,2}$, Gavin Duffy ${ }^{2}$, and Brian Bowe ${ }^{2}$ \\ ${ }^{1}$ Centre for Engineering Education at University College London, UK and the ${ }^{2}$ College \\ of Engineering and the Built Environment, Technological University Dublin, Ireland \\ University College London, Centre for Engineering Education, 2.06 Front Building, \\ Torrington Place, London, WC1E 6BT, United Kingdom, s.chance@ucl.ac.uk, +353 85 \\ 7884677
}

Acknowledgements: Data collection and transcription were supported by grants from the Fulbright Commission in Ireland and Dublin Institute of Technology. Data analysis and reporting were supported by Marie Sklodowska-Curie Actions (MSCA) fellowships from the European Union (Call identifier: FP7-PEOPLE-2013-IIF, Project 629388, Project acronym: REESP, Project title: Re-Engineering Europe's STEM Pipeline and Call identifier: H2020-MSCA-IF-2016, Project 747069, Project acronym: DesignEng, Project title: Designing Engineers: Harnessing the Power of Design Projects to Spur Cognitive and Epistemological Development of STEM Students.

Word count: 18,200 words

\section{Short biographical notes on contributors}

Prof. Shannon Chance holds a Ph.D. in Higher Education from William and Mary University and was formerly a Professor of Architecture at Hampton University. She is a licensed architect with a Bachelor's and Master's in Architecture from Virginia Tech. Shannon currently serves as Visiting Professor and Marie Curie Research Fellow at University College London, and Visiting Professor at London South Bank University. She is on career break from her permanent post as Lecturer in the School of Multi-disciplinary Technologies at Technological University Dublin (TU Dublin). She previously worked at TU Dublin as a Fulbright scholar and Marie Curie Research Fellow. She is an Associate Editor of IEEE Transactions on Education, on the editorial board of the European Journal of Engineering Education, and on the governing body of the global Research in Engineering Education Network that coordinates the bi-annual Research in Engineering Education Symposium (REES). Shannon's teaching areas include architecture and urban design, introductory engineering, Building Information Modeling, environmental sustainability, and educational planning.

Dr. Gavin Duffy is a faculty member in the School of Electrical and Electronic Engineering Systems at Technological University Dublin (TU Dublin), where he has been teaching since 2002. He received a $\mathrm{PhD}$ in engineering education in 2017, with a study focused on the role of spatial ability in problem representation among engineering students. He is a member of TU Dublin's CREATE (Contributions to Research in Engineering and Applied Technology Education) research group. He has interest in epistemological development and on how engineering education research is conducted. Prior to joining TU Dublin, Gavin worked in engineering design consultancies as both a chemical engineer and control systems engineer. At 
DIT, he delivers modules on chemical technology, instrumentation, automation, and control engineering and has been using project-based learning since 2005 .

Prof. Brian Bowe is Head of Academic Affairs and Assistant Registrar at Technological University Dublin (TU Dublin). He leads the research group called CREATE (for Contributions to Research in Engineering and Applied Technology Education) with more than 30 members. He has been active in STEM education research for over 20 years and led the development of this area in TU Dublin. In 2001, he established the Physics Education Research group that evolved between 2001 and 2008 to include education research in computer science, chemistry and engineering. In 2013, he established CREATE, which currently involves a diverse range of $\mathrm{PhD}$ research topics that he supervises, including studies of spatial skills development, ethics in STEM education, epistemological development, and the impact of pedagogy on minority students in STEM.

Geolocation: Dublin: (capital city) $53^{\circ} 20^{\prime} \mathrm{N}, 6^{\circ} 16^{\prime} \mathrm{W}$ 


\title{
Comparing grounded theory and phenomenology as methods to understand lived experience of engineering educators implementing Problem-Based Learning
}

\begin{abstract}
Getting lecturers/professors to implement pedagogical innovations is a central focus of university managers/administrators today. Convincing teachers to change is notoriously hard. This research project investigated the shift in pedagogical approach among a small group of faculty as they replaced traditional lecture-based methods with Problem-Based Learning projects. Interviews were conducted with eight of the most active drivers of this change, around the research question: What was it like to be part of a learning group focused on tangible change toward student-centered learning? Objectives of this study were: (1) to understand how pedagogical changed happened in an electrical engineering programme at a post-secondary institution in Ireland; (2) to analyse data using two different research methods to distill as much meaning as possible; (3) to describe the process, results, and findings achieved using each method; and (4) to compare and contrast the methods, asking: To what extents do the research methods of grounded theory and phenomenology fit our data and yield relevant and useful findings? Results of this mixed-methods approach show that fun, enjoyment, camaraderie, and a sense of ownership of the change at the ground level were essential to driving transformation. With regard to analysing this specific dataset, we found grounded theory to produce more helpful outcomes (including a graphic model of change). Because interviews had been conducted two years after the events under analysis, the interview comments were inherently reflective and, as it turns out, not as conducive to phenomenological methodologies which seek to understand raw, pre-reflective experience. This report should be of particular use to (a) teachers and administrators strategizing change and (b) engineering education researchers assessing the applicability of various methods.
\end{abstract}

Keywords: comparative methods; grounded theory; phenomenology; faculty learning communities; change management

\section{Introduction}

Convincing educators to implement innovative pedagogies is a central focus of higher education administrators today. Getting teachers to change is notoriously hard. This research project investigated the shift in pedagogical approach - from traditional lecture-based to increasingly learner-driven - where the use of group, Problem-Based Learning (PBL) projects was phased in and codified into electrical engineering programmes over time at one higher education institution in Ireland. To explore how to support change within education more broadly, we collected data probing individual lecturers' experiences working to transform the way they tutor students at Dublin Institute of Technology (DIT, recently renamed Technological University Dublin).

Semi-structured interviews were conducted in 2012 with eight of the most active drivers of this change. Interviews were conducted using the principles of phenomenology, and thus yielding data appropriate for analysis using either grounded theory or phenomenology. The interviews focused on topics related to one overarching research question: What was it like to be part of a learning group focused on tangible change toward student-centered learning? A visiting scholar from abroad asked interviewees about experiences that had occurred two years prior, when the interviewees had held frequent discussion, often at a scheduled time and place, to discuss how to implement group PBL projects. Among this group of educators, the term 
PBL denotes practical, hands-on, group-based project work, typically involving design and/or research.

For the academic year 2009-2010, a group of staff had met monthly to discuss learning, teaching, and assessment (LTA) issues. Meetings were organized and led by one of the staff members, who had received a teaching fellowship from the institution. His college's learning development officer assisted him in conceptualizing and conducting this group-learning project. The project they proposed would enhance and grow the number of group-based, project-driven modules in the Bachelor of Electrical Engineering programme. Working together, their small Faculty Learning Community (FCL) identified a primary theme for the group's discussion series: they wanted to learn to provide fair and valid feedback and assessment to students in Problem-Based Learning (PBL). Through open discussion, participants debated and derived support from the literature and from each other. Between discussions, they tested ideas in their classrooms and labs - sometimes alone and sometimes in pairs or groups - and they subsequently reported what happened to the whole FLC. Creating a project for themselves, members of the FLC produced a short an instructional video to illustrate effective and ineffective team dynamics.

Today, group projects are a standard in the curriculum, and every student experiences PBL projects in each year of the programme. Projects increase in complexity and open-endedness across the students' matriculation. Early projects are more clearly defined and over the years students learn to frame problems in an iterative fashion during the process of problem solving. Changes have been codified into programme documents and accreditation agreements. PBL is considered part of the ethos of the programme, and this programme is viewed by others it the institution as a leader in PBL. Specific, noteworthy programme-wide results include: a programme curriculum formalized around a spine of PBL, construction of a PBL learning laboratory dedicated specifically to the programme, and on-going allocation of budgetary and staffing resources to PBL activities. Nevertheless, the thrust of the transformation involved implementing project-driven group learning in engineering courses. New techniques were implemented and refined by a small group of teachers who met regularly to discuss LTA issues. As a peer-learning group, which today might be called a Faculty Learning Community (FCL), they adopted a core 'project' for a year, which was implementing change in their own classrooms and labs. They wanted to address many doubts and concerns: having less time for content delivery; how to advise teams in self-directed learning; how to achieve fairness in grading; and how to deal with freeloading that inevitably occurs in groups. The group's use of project-driven peerlearning groups to encourage, support, and sustain the transformation was a key feature of the process and, we believed, merited closer examination.

Rather than focus on the techniques this group developed, we sought to understand what the experience was like for them and what motivated them to change. We wanted to better understand the change that happened so that we, and others seeking to implement pedagogical change, can achieve that more effectively. Objectives of our investigation were four-fold: (1) to understand how pedagogical change happened in an electrical engineering programme at a post-secondary institution in Ireland; (2) to analyse data using two different research methods to distill as much meaning as possible; (3) to describe the process, results, and findings achieved using each method; and (4) to compare and contrast the methods. In this mixed-methods approach, we used grounded theory and phenomenology to collect and analyse data.

Results of this mixed-methods approach show that fun, enjoyment, camaraderie, and a sense of ownership of the change at the ground level were essential to driving 
change. When comparing results and findings achieved via the two different, but complementary, research methods, we found grounded theory to produce more helpful outcomes (including a graphic model of change). These findings were applicable to this particular dataset due to the time delay between the events in question and the interview dates. As interviews had been conducted two years following the events under analysis, participants' comments were inherently reflective and, as it turns out, not as conducive to phenomenological analysis which seeks to understand raw, pre-reflective experience. We believe this report can be of use to engineering teachers, change-management professionals, and education researchers assessing the applicability of various methods.

\section{Research questions}

Our interviews sought to address the following research question:

- What was it like to be part of a learning group focused on tangible change toward student-centered learning?

To distill meaning, we used two different research methods, and in the process we addressed the question:

- To what extents do the research methods of grounded theory and phenomenology fit our data and yield relevant and useful findings?

The overall study allowed us to answer two more questions:

- What implications, if any, does the learning group hold for practice? (What factors supported this change? What lessons can be learned for other engineering educators?)

- What implications does our study hold for research? (Was this method useful? Does it hold promise for research on engineering education?)

\section{Context and nature of the change}

The context for this study is a gradual move from traditional instruction to studentcentered learning that occurred over the past six years in the Bachelor of Engineering in Electrical Engineering programme at Dublin Institute of Technology (DIT). The change under investigation has been part of a widespread effort to reform teaching practice across the institution, which included the institution-wide adoption of a policy in 2009 to require all new teaching staff to earn a post-graduate qualification (certificate, diploma, Master's, or doctorate) in "learning and teaching". The case under study was visible to many, in part because it coincided with accreditation processes. It was codified into programme documents and contractual accreditation agreements via the development of coherent and constructively aligned group-based, project-driven pedagogies across a suite of three electrical engineering degree programmes.

The transformation under study included development of a strategic framework for change and integration of group-based student-centered learning pedagogies into each year of the curriculum. Understanding fundamental aspects of the transformation - and underlying factors that convinced individual teachers to changecan help educators who seek to implement similar shifts in pedagogy. In analyzing the mechanisms that fostered change in this program, and then interpreting the findings, we draw conclusions that can assist teachers, program administrators, strategists, and policy makers facilitate change in their other educational settings.

The postsecondary institution in which this change occurred has been changing rapidly in recent decades. Merging with two nearby institutes of technology, it officially became Technological University of Dublin (TU Dublin) in January 2019. The existing institution formed in 1992 as a conglomeration of a hundred or so smaller institutions scattered around the nation's capital city - the oldest dating back to 1887. At the time, 
DIT enroled 23,000 students; today TU Dublin enrols about 29,000 students. It is the largest institution of higher education on the island (the Republic of Ireland and Northern Ireland).

Within the College of Engineering and Built Environment, DIT offers degree programmes accredited by Engineers Ireland and recognized under Dublin and Washington accords. It has a reputation for practical, hands-on education. Its School of Electrical and Electronic Engineering is the largest of its kind in Ireland with approximately 75 academic staff and 1000 students at the time of the study. The School offers education at several different levels ranging from electrical apprentice to Ph.D. The Bachelor of Electrical and Electronic Engineering program graduates 50-70 students each year. The program is accredited by Engineers Ireland and recognized under the Washington Accord. A 'ladder system' exists here, whereby students can take programs in sequential levels from electrical apprentice (level 6 on the National Framework of Qualifications in Ireland), to Bachelor of Engineering Technology (level 7), then Bachelor of Engineering (level 8), Master's (level 9) and finally, Ph.D. (level 10). As a result, the school has a very broad student demographic. Students who cannot gain direct entry to a university program may join DIT at a lower point on the ladder, work their way up, and eventually sit beside those who entered directly from secondary school.

At the time of this change in teaching practice, instructors in the Institute were timetabled for 18 to 20 hours in-class per week. Continuing until today, staff members often teach the same subjects from year to year and there is a strong sense of ownership over modules by individual teachers. Although research is encouraged and the School has several highly regarded research groups, staff members devote most of their time to teaching - both in the classroom and the laboratory. Staff and students become well acquainted via close contact in labs, which have a ratio of 16 students to one lecturer. There is also a strong sense of camaraderie among educators in the electrical engineering programme under study. This is most observable in the sunny staff canteen in the penthouse of the School, which buzzes with activity and serves as a hub of conversation among staff during coffee and lunchtime each day.

During a one-week visit to the Institute in 2011, the lead researcher conducted interviews with eight staff from around the institute and noted visible pedagogical shifts occurring within Electrical Engineering. As a result, she collected the set of interviews reported here during a subsequent one-year Fulbright fellowship. She and her coauthors conducted analyses at that time, but did not publish the findings in a journal. As the findings still carry relevance and may hold keys to fostering bigger changes in this institution and beyond, we are now bringing the results and findings to press. We are also extending our findings by describing the unique comparative, mixed-method approach we used to drill down into the data.

We wanted to understand how, in a period of five to seven years, a fairly dramatic shift in education practice had occurred within the School. The change was most visible via the use of project-based learning to supplement earlier forms of problem-oriented learning (i.e., practical assignments that required less self direction and little group work). From a starting point in 2005, when the institution launched its Centre for Learning and Teaching and began to form its 2009 policy requirement, this programme had no group-based PBL modules (i.e. courses). By the time of data collection for this study, there were 12 PBL modules incorporating group-work, reaching students across three programmes. There were also examples of reform within several lecture-based modules that reflected a general move toward continuous assessment, providing more frequent formative feedback, and focusing on learning as 
opposed to content delivery. Out of a lecturing staff of 22 in the Control and Electrical Engineering Department, at least seven were facilitating learning groups by this time. In addition, five more faculty members had moved to a project-driven approach in subjects such as instrumentation, control, automation, programming, design, robotics, and electrical systems.

While the shift seems minor - at least in comparison to institutions like Aalborg (Moesby, 2002), or MIT, Chalmers University, Royal Institute of Technology KTH and Linköping University LiU (Berggren et al, 2003) - it nevertheless represented a significant development for engineering at DIT. Before this period, group work did exist in isolated pockets in programs, but was mostly found within professional development modules. Technical engineering content was not typically delivered via hands-on group work. Assessment was usually summative (via individual end-ofsemester written examinations) and teachers provided very little formative assessment to support students' learning process.

Despite heavy teaching loads and a traditional lecture-based approach, a shift did occur with the School, and this change was consistent with recommendations made by Eastman, McCracken, and Newstetter (2001), McKenna et al. (2011), the USA's National Science Board (2007), and Engineers Ireland (2007). Tangible changes were implemented at the classroom level and also incorporated into policies and accreditation-related documents at the programme level, where pedagogies shifted away from lecture-based, teacher-centered formats. Teachers showed increasing concern for the processes by which students were learning, individually and in groups. These changes remain visible today, informing teaching practice even eight years later as observed periodically by the external member of the research team.

It is important to note that discussion of LTA issues preceded and proceeded the one-year period when the FLC met monthly, in a somewhat more formal setting, to discuss and refine their strategies. This monthly FCL round-table grew out of on-going debate across the programme about the value of group assignments and the appropriate balance between content delivery (i.e., lecturing) and hands-on application (in the form of group projects). Approximately half of all teachers in DIT's electrical engineering department actively discuss LTA and student-centered learning. Frequent, informal discussions happen in the staff canteen, where faculty members drop in, for coffee or lunch. Others occur at teachers' desks, encouraged by the fact that faculty share offices in groups of four. Still other discussions happen in corridors or classrooms because faculty members often share modules - they teach identical content concurrently to different groups of students and enjoy comparing notes.

In the 2009-2010 FCL, a group of seven (five staff members, one visiting Fulbright scholar, and the College's Head of Learning Development) met once a month. Two other participated actively from the sidelines. The fellow/FCL coordinator saw all nine of these individuals as crucial to the transformation that occurred. The change effort was thus spearheaded by: (\#1) the DIT teaching fellow who had been awarded a $€ 2000$ stipend to support conference participation, (\#2) the learning officer, (\#3) one teacher nearing retirement, three people completing formal qualifications coursework in learning and teaching who were (\#4) a visiting scholar and (\#5 and \#6) two relatively new staff members, (\#7) an additional experienced member of staff, and two other members of staff (\#8 and \#9) who avoided formal meetings but engaged fully in informal discussions and initiatives set out by the group. All participants were male, reflecting the make-up of the staff at the time and the low rate of participation in electrical engineering of women overall. The avoiders, $\# 8$ and $\# 9$, resisted mandates from above; while they saw themselves as part of their programme, school, and college, 
they were not entirely comfortable with the new layers of governance they sensed were growing up outside the college. For this study, we were able to interview all these individuals except the retiree, and our sample reflected all career stages. Moreover, the sample included advocates as well as skeptics of group-based learning.

Despite their underlying disagreements, all participants supported a projectdriven approach and all enjoyed discussing such topics with their colleagues.

Participants were not compensated; they voluntarily attended. The teaching fellow invited individuals he thought could contribute constructively. The FLC thus comprised those individuals who were interested in discussing and adapting teaching practice and implementing new student-centered learning approaches. All members of the FLC sought (and seek) to provide students with formative feedback. Some of them have shifted their lab modules from traditional recipe-type experiments to self-directed projects. Others are using groups as vehicles for student learning and tutoring students on effective collaboration and team design processes.

Each month the teaching fellow identified a meeting time and issued invites. He facilitated round-table discussion alongside the learning officer. Meetings were used to share experiences, challenge ideas, and confront doubts. The fellow and the officer helped propose solutions. They directed discussion toward poignant topics, drawing from prior experiences implementing PBL and from literature on PBL.

Meetings were held in a coffee area of a nearby higher education building, rather than the staff canteen, to provide a small degree of separation from the daily routine.

The Head of Learning Development guided the group's lively conversations. He took an advisory role, and discussed his experiences at DIT of, for instance, converting a physics course to PBL (Bowe \& Cohen, 2004), supervising education research Ph.D. projects (Irving, 2010; Walsh, 2009), and reading and writing about LTA and PBL (Bowe, 2007).

A written summary report, unpublished but disseminated publically by the visiting scholar following his own fellowship provides his description of the context:

While I was learning about the primarily theoretical aspects of SCL [studentcentred learning], particularly in the lecture-based learning environment, in the Postgraduate Certificate Course held in Mount Street, I was also learning about the primarily practical aspects of learning in the group-based learning environment, by tutoring learning groups in the laboratory sessions of three different modules offered in the Electrical Engineering Department at DIT. ... While the three modules were different from each other in certain ways, they had in common that their laboratories followed a format that I would describe as consisting of a mix of [problem-based] and project-based learning.

It is intersting to note that all three modules mentioned in the quote above were led by members of this FLC and team-teaching this range of modules provided many shared experiences to discuss in their monthly round-table. FLC meetings offered a protected space for targeting and discussing concerns that had previously discouraged staff from implementing Problem-Based Learning. Meetings were used to identify problems and develop strategies that would be tested in practice, with results discussed at subsequent meetings and voiced in programme meetings. As such, themes from these formal meetings naturally spilled over, infusing the daily conversations with the larger programme staff. Shared experiences and findings of this project were voiced at formal programmeplanning meetings. Empowered by their discussions and their experience with 
implementation, members of this small group convinced colleagues and supervisors to formally adopt changes.

\section{Literature review}

Consistent with the methods used in this study, the research team identified bodies of literature relevant to the results of Phase 1 and 2. Each is summarized below: teachers' conceptions of learning, theories regarding behavioural change, Faculty Learning Communities, grassroots leadership, and self-regulated learning. Researchers on the team were aware of only half this literature before commencing the study.

\section{Conceptions of learning}

Research has identified discretely different ways of conceptualizing education, with some teachers focusing on their own behavior (i.e., what they themselves do in the classroom) and others focusing on how students learn and grow (Akerlind, 2003; Gonzales, 2011; Trigwell \& Prosser, 1996). Barrie (2007) asked teachers how and where students should gain transferable skills like teamwork and leadership. His phenomenographic study identified six discrete ways of thinking, which he arranged in a spectrum. Teachers at the teacher-focused end of the spectrum believed students should arrive at university with such skills, and should gain any lacking skills in remedial courses but not in their classrooms. Teachers in the middle of the spectrum sill focused on what they themselves did, but they also thought students could gain necessary transferable skills in the context of their regular classroom activities or through the way their discipline was taught. At the learner-centered end of the spectrum were the educators actively working to create a learning environment where a comprehensive range of activities and experiences would be provided across the campus to catalyse complex new understandings and abilities within the student. As is common in phenomenographic studies, the table presented a hierarchy, with traditional approaches at one end and holistic, integrative, and student-centered approaches at the other end.

Building on such studies, Degago and Kaino (2015) conducted interviews with 20 university instructors. They discovered that teachers who knew about and understood many pedagogical approaches were able to implement student-centered techniques as well as more traditional, teacher-centered approaches. These educators combined multiple orientations to appropriately fit the situation at hand, whereas other teachers had less breadth of pedagogical knowledge and implemented only the traditional approaches. These teachers remained unaware of and unaffected by student-centered thinking. Figure 1 illustrates the hierarchy described by Degago and Kaino, which identifies techniques to "help students expand their knowledge" as more advanced and higher-level than simply "satisfying syllabus demands". A skilled teacher can achieve both, and does not see these as contradictory requests.

Figure 1. Hierarchical categories for conceptualizing teacher's role, derived from findings of Degago and Kaino (2015). 


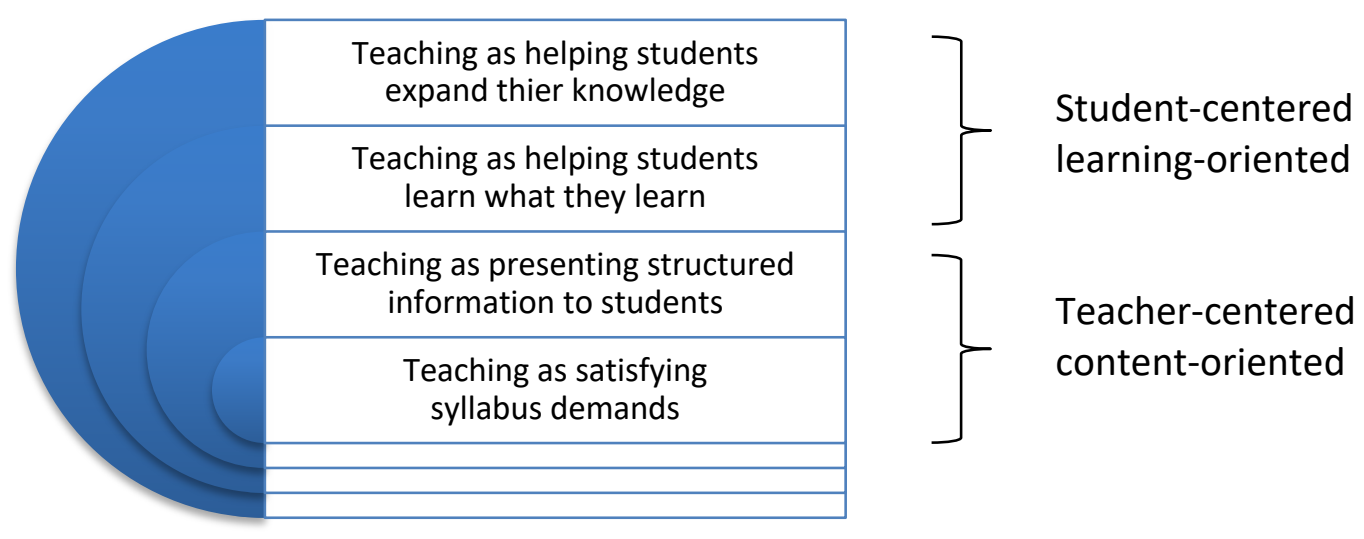

Problem-Based Learning is often categorised as a student-centred approach, although many educators assign projects without advising students on how to approach problemsolving especially when they are working in groups. Shifting focus to 'how students are learning' means observing project-group interactions and providing advice-effectively balancing the level of challenge and support that students experience (Sanford \& Adelson, 1962). Because educators behave in ways consistent with their conceptualizations, leaders must influence the teachers' conceptualizations if they want to begin shifting behaviour in the classroom (Kember \& Kwan, 2000). Bruffee (1999) found that grassroots efforts flourish when educators adopt new conceptualisations of knowledge, teaching, and learning - but also when they (a) view themselves as change agents rather than suppliers of content, (b) implement research-informed teaching methods, and (c) combine conversation with reflection.

Motivating teachers to adopt new conceptulisations and pedagogies presents a significant challenge in higher education; management has few ways to prompt change (Gardner, 2014; Rowley, Lujan, \& Dolence, 1998). Teachers, like students, need support when they are working to transform their concepts and behaviours. For many teachers, "the notion of being a learner while being a lecturer is deeply problematic both emotionally and pedagogically" (Savin-Baden, 2008, p. 145). Adopting studentcentered approaches may be particularly "daunting for faculty and require new skill sets" (Tweddell, Clark, \& Nelson, 2016, p. 7). Getting teachers to contemplate and reflect on pedagogy encouraged them to shift emphasis from transmitting knowledge toward helping students shed ineffective concepts, in a study by McKenna, Yalvac, and Light (2009).

\section{Behavioural change}

Research from the field of counseling may be of use. Prochaska, Redding, and Evers (2002) identified five stages in adopting new behaviors and converting them into habit: (1) pre-contemplation, (2) contemplation, (3) preparation for action, (4) action, and (5) maintenance. Like anyone, teachers encounter these stages when implementing a change and making it permanent. They need to be adequately prepared and supported in order to practice the new behaviours and then make it habit (Sanford \& Adelson, 1962).

Satisfaction and rewards must outweigh perceived risks and discomforts as reflected in a study by Tweddell, Clark, and Nelson (2016). Their study (of 19 pharmacy teachers who had implemented team-based learning across their programme) identified barriers such as: increased workload at the start, extra 
effort to develop new activities, and the need to learn how to facilitate learnercentered activities. Among participating pharmacy teachers, perceived benefits helped their initiative succeed. These included increases in students' peer-to-peer learning, engagement, and development of transferable skills, and staff members' enjoyment of teaching. Participants succeeded by believing the benefits to students' learning and skill development, coupled with their own personal satisfaction, outweighed the challenges they confronted. They were able to change their behaviours.

\section{Change management and grassroots leadership}

Combining bottom-up and top-down leadership approaches can have dramatic results, although Kezar and Lester (2011) assert that much more research is needed in this area. Perry (2014) recommends upper administrators help steer opinion by "creating a climate for change" while those at the base use "an organic process of collaborating with colleagues" (p. 164). Regardless of their level in the organization, the best leaders usually exude energy, hope, and enthusiasm - while endeavoring to build relationships, achieve coherence, create and share knowledge, understand change, and behave with moral purpose (Fullan, 2001).

Informal or grassroots leadership involves developing new leadership skills together, growing the group's voice and visibility, developing its ability to influence direction, and working to understand the existing culture and change it (Hofmeyer et al, 2015). It is often individual champions who provide vision for change and gather momentum and support (Black \& Gregersen, 2013). Such champions can help overcome resistance within the organization's systems and people. Grassroots 'servant leaders' convey a sense of equality (Greenleaf, 1977) and display the characteristics of listening, awareness, empathy, healing, foresight, stewardship, community-building, conceptualisation, persuasion, and commitment to the growth of others (Spears, 1998). Stories of grassroots change typically exude a strong sense of collegiality, where individuals: have the right and ability to participate in institutional affairs; hold a sense of worth and equality among disciplines; and feel they are part of "a congenial and sympathetic company of scholars in which friendships, good conversation, and mutual aid can flourish" (Bowen \& Schuster, 1986, p. 55).

\section{Faculty Learning Communities}

A peer learning group or Faculty Learning Community (FLC) can help motivate individuals to develop new competencies and empower them to enact change. In studying how small groups accomplished widespread change, Edintaite (2012) identified desirable elements: (1) individual learning occurring by all teachers regarding subjects they teach; (2) collective learning occurring among small groups of teachers about their aims and curriculum; and (3) collective learning appearing across the entire academic department to create shared a philosophy, vision, and mission.

FLC approaches are being implemented widely in engineering in the USA now, as evident in the survey of 2,503 STEM faculty members involved in grant-funded communities of practice to promote institutional and departmental reform in Higher Education (Gehrke \& Kezar, 2017). A recent report of outcomes of the NSF program for Revolutionizing Engineering and Computer Science Departments found that with faculty learning "teams reported significant negotiation at the onset of the project. First, teams reported the need to re-situate their collective understanding of the project itself, including how the project fit into the current vision of the operations of their institution.... Second, teams negotiated communication strategies and key messaging to 
outside parties (e.g., the remainder of the department members)" (Ingram, Litzler, Margherio, \& Williams, 2017, p. 1). Lastly, teams had trouble explaining how they implemented change theories. Reports from individual teams that participate in this NSF program are emerging (Sweeney, Koretsky, Bothwell, Nolen, \& Montfort, 2017) and they provide insight into cases like ours.

Cross-disciplinary Faculty Learning Communities can also be quite effective in spurring change, as the case where "six professors representing different disciplines came together to study, develop, and teach blended learning courses" (Wicks, Craft, Mason, Gritter, \& Bolding, 2015, p. 53). These teachers found they benefitted most from their FLC via "helpful advice on promising practices and encouragement when experiencing instructional or technical challenges" (p. 53). Learning in groups can be a motivating force (Blumenfield, Kempler, \& Krajcik, 2006). Collaborative learning can help dissolve disciplinary boundaries and create new knowledge for the benefit of society (Kerr, 2001).

\section{Self-regulated learning in groups}

For many years, scholars have studied social influence - forces groups and people exert on the motivation of individuals. Recently, researchers began investigating the social environment within groups and looking at co-created aspects of motivation. "To advance our understanding of motivation in collaborative learning, both individual and social processes need to be considered" (Järvelä, Volet, \& Järvenoja, 2010, p. 15).

Like individuals, groups also need to reflect and to regulate their own learning as they move toward more sophisticated behaviours (Volet, Vauras, \& Salonen, 2009). Teams aiming to produce revolutionary new knowledge can gain from crossing disciplinary boundaries, learning through group projects, and integrating as well as generating and sharing knowledge (Fong, 2003). Such teams must access supportive resources and evaluate success; this requires reflection and metacognitive awareness (McKenna et al, 2009). Regulating one's own learning and the learning of the larger group is essential to collaborative learning, because individuals and groups alike face social and emotional challenges in the process of learning and conceptualizing and much more research is needed on "enacted, dynamic, and social processes" (Järvelä, Volet, \& Järvenoja, 2010, p. 19) occurring within groups as they learn.

The term Socially Shared Metacognitive Regulation (SSMR) describes selfregulation that happens within learning groups. As suggested above, investigations of SSMR stem from prior research on individuals - research that considered social, cognitive, and self-regulating aspects of their individual learning (Pintrich \& Zusho, 2002; Zimmerman, 1990). For example, Rogat and Linnenbrink-Garcia (2011) observed school children studying math in groups and found an association between quality of work and the use of specific behaviours to self-regulate the group's work. These behaviours were planning, monitoring, and engagement. "Positive socioemotional interactions and collaboration" (p. 375) were linked to high-quality SSMR.

Subsequent research with older students confirmed such findings - that working in groups that 'feel good' helps encourage and promote change - and extended them. A study of five teams of postsecondary students (de Backer, van Keer, \& Valcke, 2015) found when students worked together - to understand concepts, construct knowledge, and solve problems together - they also learned to reflect on how they were thinking and to regulate their own patterns of collaborative learning.

\section{Research programme}


By analysing data in multiple ways we pushed our understanding of the phenomenon further. We actively and iteratively discussed results and interpretations, identified assumptions, debated points of departure, and triangulated findings. Combining methods is, of course, not always appropriate. The type and format of the data must fit the techniques used for analysis. As Creswell (2013) asserted, the ontological issues, epistemological and axiological assumptions, must align in logical ways with each other and with the methodologies used. Because phenomenology and grounded theory are so similar in nature, the data we had collected were appropriate for either type of analysis. Both fall into the constructivist paradigm which relies on "Prolonged engagement in the field" and "Thick, rich description" where the researchers seek "Disconfirming evidence" to increase validity (Creswell \& Miller, 2000, p. 126) - these were clear characteristics of our study. Overall, constructivist approaches focus on: understanding, multiple participant meanings, social and historical construction, and theory generation (Creswell, 2007, listed on p. 6). Both phenomenology and grounded theory are interpretive research methodologies situated in the constructivist epistemology.

In this study, we conducted both grounded theory and phenomenology as means to understand our data as fully as possible, and to discover which method worked best for us and why. Campbell and Fiske (1959) introduced the practice of using multiple methods to study qualitative psychological traits because "early thoughts about the value of multiple methods - called mixed methods - resided in the idea that all methods had biases and weaknesses" (Creswell, 2013, p. 14) and means were needed to overcome those weaknesses. Since then, many scholars have published books identifying both grounded theory and phenomenology as established methodologies and providing descriptions of both techniques (Charmaz, 2014; Denzin \& Lincoln, 1994, 2011; Grbich, 2013). Numerous studies have been conducted using two or more methodologies (Alonso, Soria, \& Gozalo, 1991; Bergeron, Buteau, \& Raymond, 1991; Isaacowitz, Wadlinger, Goren, \& Wilson, 2006; Lenderink, Buishand, \& Deursen, 2007; Sedgh, Rossier, Kaboré, Bankole, \& Mikulich, 2011; Seifert, 1995; Vera, 1990), but most used quantitative methods even when social issues were studied.

Nevertheless, science education researchers Davis and Callihan (2013) argue for using multiple methodologies; they encourage researchers to take a pragmatic approach and to identify the methodology best suited to their specific research question rather than simply relying on whatever methods they know best. By using multiple approaches, we were able to more fully analyse the data, looking at the individual level to "Focus on meaning made by individuals as by products of interactions", as well as the collective level to "Focus on how group makes meaning between members" (Davis $\&$ Callihan, 2013, p. 513). Since our questions spanned individual and collective experience, both grounded theory and phenomenology were appropriate. According to Davis and Callihan, both methodologies work for studying individual experience. They list as appropriate for study of collective issues both hermeneutics (e.g., Moustakas' 1994 transcendental, hermeneutic phenomenology) and dialogue analysis (e.g., grounded theory). Note that not all forms of phenomenology are hermeneutic - Giorgi's (2009) phenomenological method is purely descriptive, for example.

In Phase 1, we used grounded theory. We analyzed data via the constant comparative method (open, axial, and structural coding techniques) defined by Strauss and Corbin (1994) along with template analysis (King, 2004). We analysed results, interpreted findings, and generated a graphic model for use elsewhere. In Phase 2, we took the same data and conducted phenomenological analysis. We studied several different scholars' methods for conducting phenomenological analysis, including van Manen (1990) and Giorgi (2009) before selecting Moustakas' (1994) method. In this 
phase, we sought to master the use of Moustakas' analytical method. In Phase 3, we compared what we had learned using the two different methods and situated the findings from Phase 1 and 2 in the literature. In this way, we considered how our results fit pre-existing theories and models. In the sections directly below, we describe the research team, the composition of the sample group, and the interview protocol we used to generate data that we could study.

\section{Research team}

Research for this project was led by a female visiting scholar, a 2012-2013 Fulbright Fellow who had not been part of the FLC, and had arrived after the changes identified in this paper had been institutionalized. She holds a $\mathrm{PhD}$ in higher education and prior to this project, she had conducted interviews in 2011 with administrators in the institution and some of the participants in this study, to better understand the institution's policies on learning and teaching and their affect in the classroom. In light of those interview data, she designed the study reported here. Both the FLC teaching fellow and college learning officer assisted the visiting scholar with scheduling interviews as well as analysing and interpreting data; they were co-authors on this study, working to ensure valid interpretation of results. The research team secured ethics approval prior to commencing work, provided informed consent, and ensured anonymity. The team conducted member checks at multiple points in the process by disseminating full drafts of the paper and receiving feedback from several participants.

All three authors were experienced PBL educators (Barrows, 1994; SavinBaden, 2008), with two of them specializing in educational planning and change management. Two had lead the change process and one (the lead author) was a visiting scholar from the USA at the time. Throughout the project, our thinking was influenced by literature on student-centered pedagogy, conceptualisations of learning and teaching, epistemic cognition, and change management.

The Fulbright fellow transcribed interviews in full prior to analysis. She (the first author) and the FLC teaching fellow (the second author) conducted data analyses in the year following data collection. These two authors worked in tandem using techniques of grounded theory and transcendental phenomenology. They gathered advice periodically from the learning development officer (the third author) who had prior experience with phenomenology. This combination of emic (internal) and etic (external) perspectives helped increase the trustworthiness, usefulness, and validity of findings.

\section{Composition of the sample group}

Eight members of staff were interviewed for this study. They represent all stages of the career ladder from new-entrants to near-retirement. All participants were male, reflecting the demographics of the School at the time of the formal FLC meetings. The sample included six of the seven members who committed to the more formal operation of the group during the academic year 2009-2010 (the one who had recently retired declined to provide an interview). The sample also included two mid-career faculty members who are frequent and active participants in informal group discussions. These two consciously avoided the formal meetings but nonetheless discussed issues with these colleagues daily and participated in implementing the change. We included these two staff members because they were important in implementing the change and informally discussing topics brought forward by FLC participants. Talking with them provided insight into the wider set of motivations held by teachers in the program. Of 
note, five of the nine active participants had taken or were taking coursework from the institute's center for learning and teaching.

Samples of this size are commonly accepted in qualitative studies investigating social and experiential phenomena. In this project, we were able to engage almost everyone who shared the experience of FLC discussions. Even in cases where the target population is larger, qualitative and phenomenological methodologists recommend limiting the sample size, to allow the researcher to delve deeply into the phenomenon. Specifically, Dukes (1984) recommended a sample size of 3-10 for phenomenology (cited in Creswell, 2007). Guest, Bunce, and Johnson (2006) reviewed literature and identified sample sizes of 5-25 in phenomenological research; Mason (2010) recommended including at least six participants in such a study. Viewed in this light, our sample size of 8 is reasonable.

\section{Interview protocol}

Interviews were conducted in autumn 2012 by the principle author, a visiting scholar $(2012 / 13)$ who had not been a member of the learning group. Participation was voluntary. Interviews lasted 60-90 minutes and were used to obtain a full description of each participant's experience of being a member of the learning group during this period of change. The process resulted in data appropriate for analysis using grounded theory as well as phenomenology.

Phenomenologists typically collect data via open-ended or semi-structured interviews (Kvale, 1996; Moustakas, 1994). They view participants as co-researchers, asking them to describe what happened and how they experienced it. An example set of interview questions is included in Appendix A. Our own hour-long, semi-structured interviews used techniques recommended by Patton (2002) as well as Moustakas. After introducing the general topic of interest (experience of this group while implementing PBL), the interviewer asked each participant to describe, in as much detail as possible, the physical setting of the group's discussions and any specific details they remembered. She set a tone of open conversation and encouraged interviewees to raise topics that were most memorable. She asked questions regarding the physical setting to ease participants' minds back to the time of the discussions, which had been held two years earlier. Emphasis was placed on what happened and how it felt, rather than any subsequent reflection or analysis that occurred by the participant. Participants were encouraged to describe aspects of the event that they might not previously have considered. They were specifically asked about emotions they encountered including frustrations and doubts, sense of accomplishment and/or pride.

A focus on emotive issues during data collection and analysis helped the research team identify key meanings embedded in the social context and assess how being part of this group affected the individuals' approaches to, and conceptualizations of, learning and teaching.

\section{Achieving validity and trustworthiness}

We used multiple techniques as a way to enhance validity and trustworthiness, including peer debriefing, data checks, member checking, and parallel/simultaneous analysis. For the grounded theory and phenomenological phases, we read multiple sources for technical guidance and we adopted a specific set of recommendations in each phase to guide our work. In the grounded theory phase, we relied on Strauss and Corbin (1994) and King (2004) for technical guidance. For the phenomenological phase, we stuck as closely as possible to Moustakas' (1994) core techniques of 
"Epoche, Phenomenological Reduction, Imaginative Variation, and a Synthesis of Meanings and Essences" (p. 41).

Throughout Phase 1 and 2, we held many peer-debriefing sessions where we challenged each other to consider statements as fully and as openly as possible. Together, we contemplated alternative interpretations and integrated literature from fields introduced by each research partner (as recommended by Creswell, 1994; SavinBaden \& Fisher, 2002). During debriefings, we also rechecked transcripts wherever we disagreed or were unsure how to interpret results (as per Moustakas, 1994). We engaged participants in member checking at several points in the process, asking them to review our descriptions and confirm accuracy (as per Creswell, 1994; Moustakas, 1994).

The framework described by Davis and Callihan (2013) confirms that our aims, goals, and quality criteria properly align to support trustworthiness. Our questions regarding individual tutor's experiences aimed for understanding, with quality criteria of sincerity and trustworthiness and a goal of truthfulness. Questions at the collective level aim at shared understanding and consensus, with quality criteria of authenticity and fairness and a goal of justness.

\section{Phase 1: grounded theory}

Using a grounded theory approach to study this phenomenon allowed findings to emerge from the data, rather than comparing data to an a priori theory or framework (Grbich, 2013; Strauss \& Corbin, 1994).

\section{Grounded theory methods}

In Strauss's view, the purpose of grounded theory is to raise generative questions "in order to develop concepts and propositions and to explore their relationships" (Grbich, 2013, p. 82) and also to validate categories and findings through the on-going process of data analysis. Our work involved transcribing the interviews, reading them in their entirety, and then taking them one by one to conduct coding - using established methods for open, axial, and selective coding (Grbich, 2013). This Phase was conducted from the perspective of higher education leadership and change management. Interviews with the learning development officer and the FLC organizer were analysed first, followed by interviews with active and less-active participants. In this way, we were able to assess agreement and points of departure.

We used open coding to look at the meaning of each individual phrase and label it. In this process, themes emerged that had similarities. Consistent with practices for axial coding, we clustered common themes together-refining, consolidating, naming, and renaming the clusters for increasing accuracy as more and more interview data were analyzed. Axial coding also involves "taking one core category that has emerged in open coding and linking it to all the subcategories that contribute to it" (Grbich, 2013, p. 86). During axial coding, we began to group the open codes by category using a table format, and started to identify relationships between these categories. This tabular format is typical of template analysis (King, 2004). It is appropriate for, and frequently implemented in, studies using grounded theory (Länsisalmi, Peiró, \& Kivimäki, 2004). As noted above, we developed the initial template while analyzing three interviews, selected to represent diverse perspectives on the phenomenon under investigation (i.e., the learning development officer, the teaching fellow/FLC organizer, and one of the newer members of staff). With the addition of each new interview transcript, we used axial coding to break the text into individual phrases and then assessed the phrase for fit with the template, modifying the template as needed to accurately fit the entirety of the data (King, 2004). Using this process, we were ultimately able to achieve selective 
coding in the Straussian tradition, wherein "you validate the relationships between a nominated central core category ... by the drawing together of additional categories of context, conditions, actions, interactions and outcomes" (Grbich, 2013, p. 86) and generating new theory.

\section{Grounded theory sub-questions}

For this phase of the study, we identified sub-questions to support the overarching research question. The first of these was: What was the role of the learning group within the transformation process? We wanted to know: Was the group needed? Was it helpful? Would the change have been as successful without the group? The second of these was: What characteristics determined it success? Specifically: What convinced group members to implement new techniques? How can the same approach be used in a different context?

\section{Grounded theory results and discussion}

Topics of discussion ranged from perceived roles and characteristics of various participants to aims, concerns, and motivations cited by participants. Appendix B provides the template/rubric resulting from Phase 1 analysis. Each box in the template contains one theme, or set of similar ideas, that emerged. Each theme was given a title that appears as a heading above the box. The themes fell into four discrete categories corresponding to the roles of key players. Thus, each column in the template lists comments and themes having to do with one of these four essential roles: the sage, the champion, the group members, and the institution.

Overall, participants were motivated by a sense of collegiality and curiosity that focused on education. They were able to maintain focus because they enjoyed discussing the topic and because they, and the champion, persistently introduced new ideas and posed LTA topics for discussion. The presence of a sage advisor helped raise confidence and momentum on LTA issues. This advisor provided examples of: how literature had been used in physics education at this institution; what frustrations students and teachers expressed in physics; what expert consultants had advised over the years; and how the learning and teaching center had developed. Group members shared interests and values, and their experience in professional development programmes offered by the Institute also supported this transition. Although they were asked to give an extra hour per month to the formal effort, they did not see this as an added burden. The work they did fit within the coffee and lunchtime discussion they would normally have. We developed a range of graphic models to illustrate the phenomenon participants described, including Figure 2.

Figure 2 links DIT's initiatives to Rogers' (1962) Innovation Diffusion Model. According to Rogers (1962), innovators and early adopters represent $16 \%$ of any given population. They counter-balance another $16 \%$ of the population that lags behind with regard to change. The bulk of people, a full $68 \%$, fall in the middle. Some of these people (known as the "early majority") will implement change sooner than others. In the electrical engineering programme under analysis, the champion was an innovator, members of the FLC peer group were early adopters, and other members of the staff (including our interviewees resistant to formality and others who got drawn into the issues via coffee and lunch discussion) can be seen as the early and late majority. As leadership theorists commonly note, any transformation will have its laggards (there are still people using VHS tapes, for instance), and in most cases $10 \%$ of people in a group will perpetually resist the change. In this case, laggards are likely to retire sooner than others. Leaders needn't focus on the individuals' opinions they cannot change, but can 
implement strategies to focus attention away from them, in cases where they are distractingly vocal. Describing a 'garbage can' model of leadership, Birnbaum (1988) explains that university leaders can limit which attractors are allowed to contact one another by sending issues to separate committees (i.e., separate 'garbage cans').

Likewise, complementary forces can be brought together for cultivation, as the teaching fellow arranged to do with the help of his learning development officer.

Figure 2: Factors driving adoption of learning/change (Source: Chance et al., 2013).

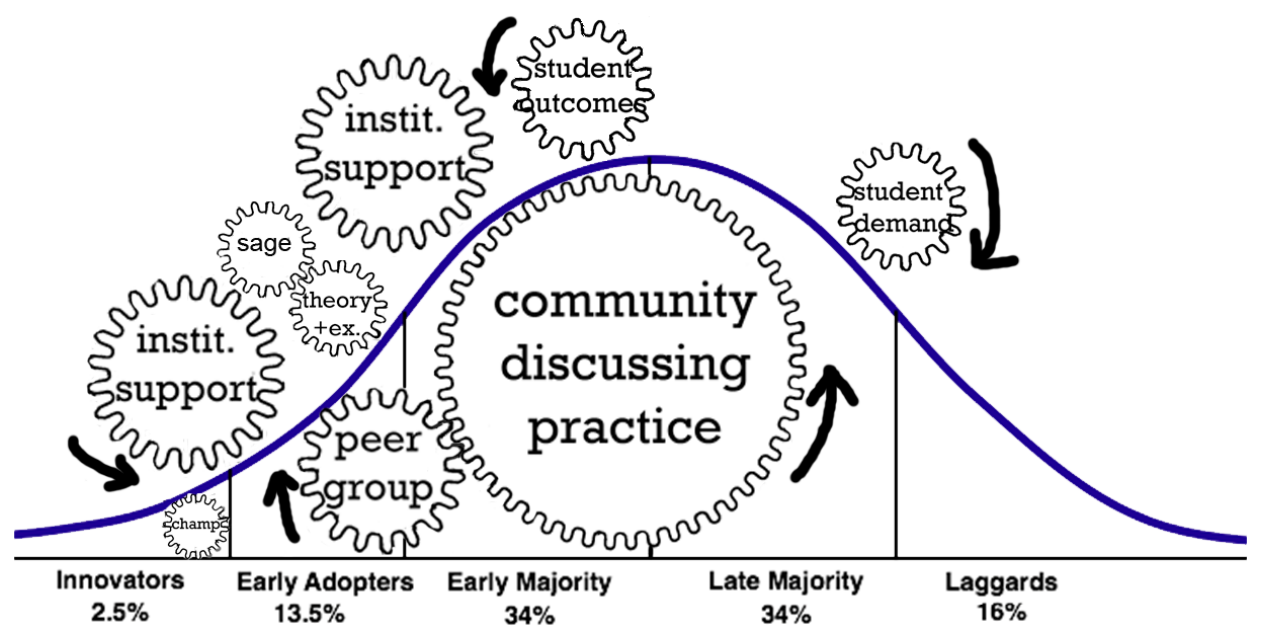

\section{Resulting theory/model}

Throughout the grounded theory process, we created: (a) diagrams alongside our coding and (b) an audit trail to enhance the reliability and validity of our findings. The diagrams we created identify aspects most crucial to this localized change process; they illustrate how various components worked together. In the diagrams, we represent key elements of the higher education organization as gears-inspired by Birnbaum's (1988) analogy of higher education systems as coffee grinders where the inner workings are shrouded in opaque covers and the causes of change are difficult to discern. Forward movement, in this case, is synonymous with change. The case illustrates that when energy is applied to key components in an education program and the system is properly aligned, small players can drive big changes (see Figure 3).

In the carefully aligned system in Figure 3, institutional programmes and policies are not able to move many individuals themselves. Their energy transfers to individuals via champion(s) and sage(s) who help groups of individuals work together to learn and to enact change. At DIT, this created a sense of movement that has encouraged more and more individuals to get involved and to implement changes. Prochaska, Redding, and Evers (2002) described the process wherein individuals contemplate and adopt new behaviors. In Figure 2, the belt that gets transported across, from left to right in this machine, represents this process. According to the sage:

Now you have early adopters... in terms of pedagogy, who have the justification, the rationale, thought through. Evidence that it works elsewhere, and so on and so forth. You have those people supported by management who are now trying to develop it through. So they establish their pedagogies, and then, like in the case here, you grow that pedagogy, you get more and more people involved and you start seeing the benefits of it. 
As like-minded teachers joined together, they encouraged each other to continue to learn and reform teaching practice. Others could see the benefits in terms of enthusiasm on the part of staff and the high levels of engagement achieved - with students spending many hours working on their projects outside of formal class hours, working in the new PBL space throughout the day and into evening hours.

Figure 3: Model for multi-level learning

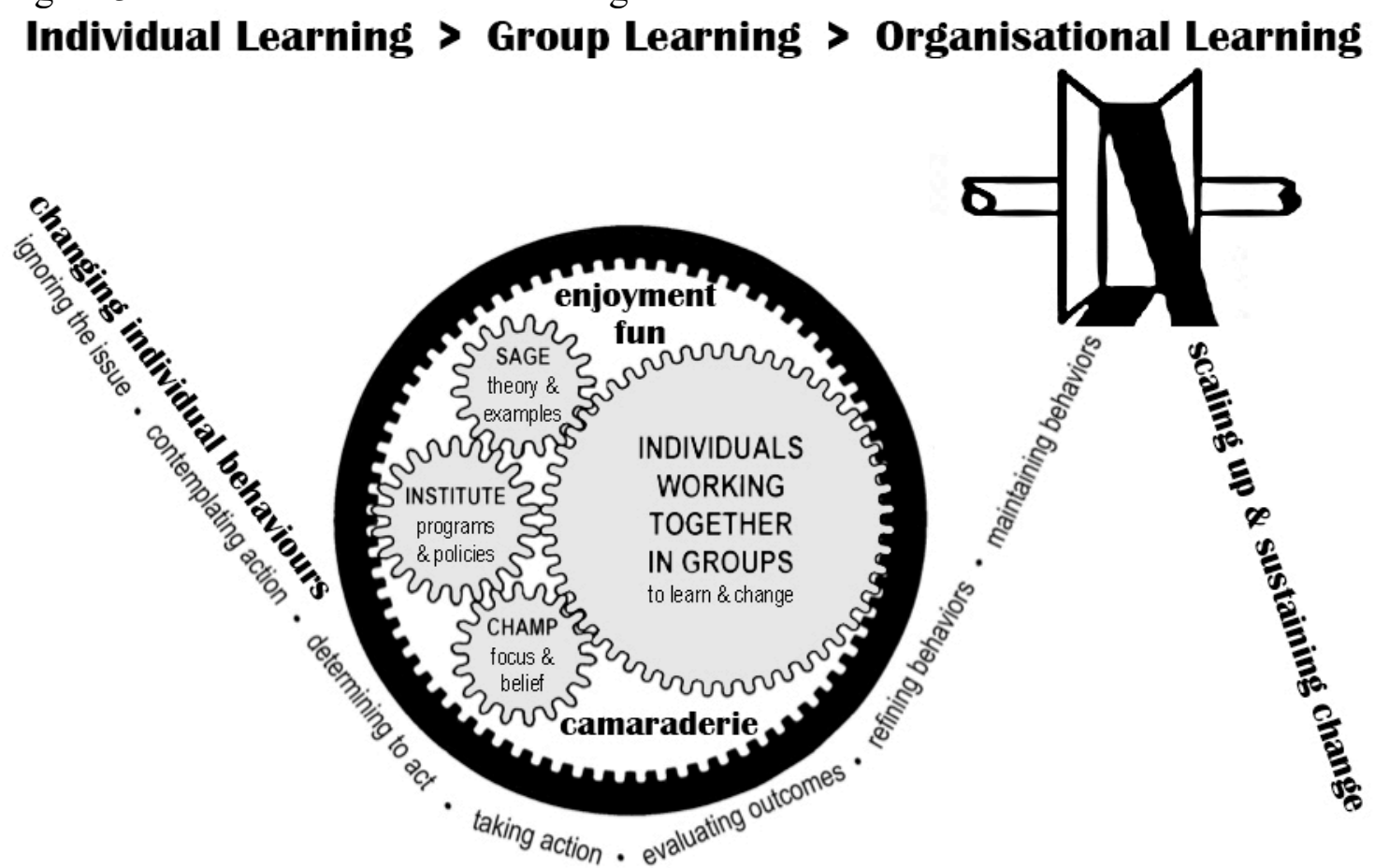

At DIT, with increasing personal involvement, the changes scaled-up and became more sustainable. This suggests triple loop learning, as described by Senge (1991), has at least begun to occur. Alignment of the central gears is crucial; in this diagram, there is almost no tolerance for error. The central change mechanism that drives action-by linking organizational intention (i.e., the Institute) to the Individuals Working Together in Groups - has only the minimum amount of clearance needed to succeed.

This case illustrates how individual professors (who are relatively small gears in the engineering education system) can leverage the resources they're given and use it to cause visible change. It shows how individuals can elicit system-wide transformation. At this institution, teachers used their own group-based learning to amplify their efforts - by implementing student-centered pedagogies across the program. What emerged in the course of this study was a clear picture of the value of aligning institutional support behind a dedicated champion and providing sage advice from an experienced practitioner. The element of this system that actually enacted curricular change, however, was the group of individual instructors who-working together as a team-devised, tested, and refined new approaches in their classrooms. Here, the individuals are working together in a special kind of environment where they are motivated by fun, interesting, and thoroughly engaging conversations with others who are seen as friends. This has helped them draw more and more individuals into the change process. By examining their experiences closely, we were able to address sub-questions:

What was the role of the FLC within the transformation process? 
Although this learning group was not the only driver behind the transformation that occurred, its members believed the formation and operation of the group epitomized and/or drove the changes that unfolded. Because the FLC was central to a range of key decisions, the group's role and function seemed to merit exploration. We studied this example in detail hoping that learning groups could be established and facilitated within other contexts where transformation is desired. The group provided an effective way of learning about, and overcoming, challenges associated with facilitating and assessing students' group work.

Participating in a group allowed the teachers to experience group work themselves and begin to regard it as an effective and enjoyable way to learn. Misgivings and doubts about group-based learning - such as issues of fairness associated with assessing each individual's performance and skills - were aired and dealt with in a satisfactory way. Through group discussions, faculty members realized there were universal challenges, ones common to all student-learning groups. Participants developed a greater awareness and confidence in managing groups. This opened the door for the inclusion of learning, design, and teamwork as assessment criteria for a number of modules offered by various teachers in the FLC. This, in turn, created the opportunity for sustained delivery of groupbased, project-driven modules in the first, second, and third years of the electrical engineering programme-wherein feedback on such skills is now routinely provided. Today, students are required to develop and demonstrate group-work skills on a continuous basis - a situation that did not exist when the FLC started.

In referring back to the literature on leadership and change management, it is evident that this faculty learning group benefited from leadership by individuals who conveyed purpose, trust, and hope (Black \& Gregersen, 2008; Fullan, 2001; Kouzes \& Posner, 2007; Sergiovanni, 2007). By the time of these interviews, more than two years after the FLC commenced, members of the group and their colleagues continued to identify and address issues that emerged related to the group's theme. They planned for discussions and instinctively followed up.

The presence of the group crystallized participants' commitment to specific issues. By bringing individuals together into a formal discussion group, the champion of this effort brought a sense of focus and accountability to specific issues and he was able to exponentially amplify the effects of his literature review and research. Although the champion could have conducted the teaching fellowship using other mechanisms (such as literature review and paper writing alone), such activities may not have generated such enthusiasm and buy-in from so many colleagues.

The existence of the formal FLC emerged as an essential feature of transformation. It increased accountability by: (1) placing certain issues in the forefront; (2) encouraging development and implementation of new practices; and (3) providing a public forum for the discussion of results. The FLC offered a structured time and place for participants to return to specific issues, discuss how various efforts had panned out in the classroom, and collectively explore avenues for further development. The FLC gave members confidence to try out new approaches - even ones that they felt tentative about. All members of the group were learning together. Even skeptical staff suspended disbelief long enough for the group to make strides implementing and refining innovative techniques. The criticism that did occur generally served to strengthen the group's overall approach, rather than undermine it. Over time, naysayers came to champion certain aspects of the pedagogies, although not the entire set of PBL values.

What characteristics determined it success?

In researching engineering education, Kolmos (2002) commented that teaching staff are 
rarely the drivers of change, yet participants in this study viewed this as a bottom-up effort. The process was initiated and grown from the ground level. Although top-down support helped enable this change, support from above would not have been adequate, in and of itself. The transformation that occurred required the formation of a group with enough clout and determination to sustain focus and build momentum. Camaraderie helped individual participants overcome inherent challenges; the champion and sage provided crucial knowledge and leadership. Together, the participants, champion, and sage identified issues of importance, researched and discussed them, developed approaches, collected resources, and galvanized support for implementation.

One participant said that 2007 was a critical moment in changes because three new staff all completed the Post Graduate Certificate in Learning and Teaching at that time:

\section{I would say that [their completion of the institution's capacity-building programme] was roughly the tipping point for dramatic increase in emphasis on assessment of process rather than just product in [the robot-building module].}

A group-PBL approach was implemented in a design module in the first year of the B.Eng. programme and this became the foundation for subsequent change. Moreover, the three people he identified later became the core of the FLC. Within and beyond this FLC, a key has been cultivating morale. One participant (a programme coordinator) stated that Institute's organizational system was poor at engaging individuals but that managing morale was not problematic in this particular effort. Participants effectively managed morale themselves.

All told, this change would have been impossible without enthusiastic, engaged teachers who enjoyed working together, exploring issues, and defining challenges for themselves. Once the teachers here found joy in discussing such topics (and reason to return to specific topics regularly) they found all sorts of ways to discuss them. Thus, the primary motivators for the people who implemented this change were intrinsic and social. The sage described them as 'reflective, enthusiastic' teachers who analyzed the effectiveness of their job from the students' perspective.

We now believe the approach of using FLCs to facilitate change in engineering education holds promise because participation in a peer learning group can appeal to faculty members who would otherwise who resist formal change initiatives and/or interacting with administration. An interesting point is that, in this institution, fewer external rewards (promotion, tenure, raises, and the like) are tied directly to performance than is typical in institutions in the USA (research- and teaching-intensive universities alike). The faculty here get to choose if they want to engage in research, if they want to seek external funding for research, and if their research will focus on technical or educational issues. The freedom they enjoy means some choose to spend their time researching and developing pedagogy.

\section{Phase 2: phenomenology}

In the second phase of our work, the research team used phenomenology. This term has multiple meanings and thus warrants clarification. Physicists, philosophers, and social scientists commonly use the term in their efforts to understand phenomena of the natural or social world. They aim to identify core, universal, or shared aspects of a given phenomenon and describe its essence. As social scientists, we use phenomenology as a method for understanding human experience of a given phenomenon. As such, we focus on collecting experiences of the world that are stored in the mind, interpreting them, and 
distilling the essence of the experience into concise descriptions.

In medicine, applications of this method deal with patients' experiences of phenomena including illness, pain, recovery, and bereavement (Laverty, 2003). In psychology, the method has been used to study experiences like depression and searching for the meaning of life (Moustakas, 1994). Today, phenomenology is increasingly popular in education research and can bridge subjects like health and education. By using phenomenology to study nurse educators as they shifted from 'learning to teach' toward developing high-level conceptualizations and competence, Gardner (2014) provided a relevant precedent for the current study.

\section{Phenomenological methods}

From among the wide range of phenomenological methods available, we elected to use the approach by Moustakas (1994), which Creswell (2013) described as well-structured and clearly defined. Creswell also provided a diagrammatic "Template for Coding a Phenomenographical Study" (Creswell, 2013, p. 170) that follows recommendations by Moustakas and includes the following items in sequence: (a) Epoche or Personal Bracketing, (b) Significant Statements, (c) Meaning Units, (d) Textural Description, and (e) Structural Description. Moustakas (1994) identified particularly difficult aspects of his method:

\footnotetext{
Phenomenology, step by step, attempts to eliminate everything that represents a prejudgment, setting aside presuppositions, and reaching a transcendental state of freshness and openness, a readiness to see in an unfettered way, not threatened by the customs, beliefs, and prejudices of normal science, by the habits of the natural world or by knowledge based on unreflected everyday experience ( $\mathrm{p}$. 41).
}

The research team read transcripts with the purpose of extracting descriptions of experiences. Together, the team developed textural, structural, and synthesized textural-structural composite descriptions to achieve full understanding of the phenomenon.

Moustakas (1994) explained that texture deals with what happened, whereas structure deals with how it was experienced. Textural aspects are pre-reflective whereas structural aspects integrate various types of thought and judgement. Although each affects the other, focusing on each component individually can promote richer understanding of the phenomenon. To recognise the difference, consider for a moment the phenomenon of a starry night. The textural description explains the actual experience of gazing at the star-filled sky, whereas the structural description is affected by the intentions and prior knowledge each participant brings to the experience, which influence perception. Texture could involve going outside, gazing upward, and feeling the cool evening breeze. As for structure, one person might have experienced it with wonder and felt nothing but love and wholeness, where another felt cold and bored, and another frustrated by viewing this from a prison cell and longing to be free.

\section{Textural analysis process}

Moustakas (1994) called the sequence of textural analysis 'Phenomenological Reduction' and he recommended four specific steps. First is Bracketing, or Epoche, which requires setting aside, to the greatest extent possible, all preconceived ideas, assumptions, opinions, and 'everyday knowledge'. This is done in order to see anew, with naiveté, and open oneself as much as possible to meanings embedded in the data. Via bracketing, we sought to omit value judgements, after-the-event reflections, and 
interpretative statements offered by our participants. As such, we initially cast aside all statements of opinion and reflection during analyses, focusing our attention instead on descriptions of the lived experience.

Moustakas' (1994) second step involves Horizontalizing, or treating every statement as equal in value to every other statement. To achieve this, we reviewed one transcript at a time to identify all non-repetitive meaning units. We flagged each individual statement or phrase carrying a distinct idea related to 'being part of this group'. Then, as we coded across the full set of transcripts, we conducted 'phenomenological reduction' by merging similar or repeated meaning units to form a single, overall list of invariant meaning units. Vagle (2014) claims horizontalizing can be conducted in stages if needed: (1) listing meaningful statements and making preliminary groups of ones with similarity; (2) reducing and eliminating repetition thus identifying 'invariant constituents'; and (3) clustering the invariant constituents and using these to determine themes.

After determining which meanings dealt with texture, we studied them and began the third step in the process-Clustering Horizons into Themes. We identified three major themes running across the invariant meaning units. In the last step of this textural-definition process we were Organizing the Horizons and Themes into a Coherent Textural Description.

\section{Structural analysis process}

We began structural analysis using Moustakas' (1994) concept of Imaginative Variation to consider alternate outcomes. As such, we asked: What happens if a specific aspect of our description is omitted? Does that affect interpretation? How? We identified parts of our description that could be left out without weakening its overall validity. Hypothetically swapping out various elements of the scenario allowed us to challenge and test the descriptions we had derived. Sub-steps of this process included: (1) systematically varying structural meanings (about individuals' perceptions) that underlie their experience of the phenomenon; (2) identifying themes and contexts that underlie and allow the phenomenon to appear; (3) giving consideration to universal structures such as "time, space, bodily concerns, materiality, causality, relation to self, or relation to others" (Moustakas, 1994, p. 99) that precipitate the thoughts and feelings people experience alongside the phenomenon; and (4) pinpointing examples that adeptly illustrate structural aspects to create a structural statement.

\section{Synthesis}

Finally, we achieved synthesis by creating a composite statement that describes core aspects the participants' shared experience. Using Moustakas' (1994) process yielded summaries of core aspects of the phenomenon that could not be changed or altered without affecting the overall experience described by participants.

\section{Phenomenological results}

Analysis in this phase focused primarily on the members of the group, rather than leaders/organizers of the discussion. The leaders really wanted to know what participants (e.g., followers) experienced and how it felt to them to be part of the group. Through Epoche and then Horizontalizing we were able to identify themes. As noted above, we used the steps identified by Vagle (2014) for horizontalizing: (1) list and group meaningful statements; (2) eliminate repetition to identify 'invariant constituents'; and (3) cluster these and determine themes. Through this process, we uncovered participants' phenomenological statements about what it was like to be part 
of a learning group in a school where tangible change towards student-centered learning was occurring to be distributed across three themes: (1) attitudes and feelings about having discussions, (2) factors influencing their desire to participate, and (3) interactions and roles within the group.

Attitudes to and feelings about having discussions

- Wanting to have conversations about Learning, Teaching, and Assessment

- Wanting to be part of group discussion; looking forward to meetings; fun and enjoyment

- Having interesting conversations about LTA

- Trusting other members of the group

- Friendships being deepened

- Being comfortable to discuss LTA in informal settings

Interactions and roles within the group

- Learning from others

- Barriers do not exist to discussing LTA with colleagues

- Input of those at a similar level of understanding of LTA is valued

- Sharing one's own ideas from practice, offering them for feedback, and receiving feedback

- There is a champion who advocates change and evangelizes others to adopt PBL

- Different viewpoints on LTA are raised and considered

- Being persuaded by others to think a different way about LTA

- Being carried along by others

- Persuading others to see things differently; convincing others to change

- Hearing ideas overflow from formal sessions

- Formal capacity-building workshops and programmes help develop a shared vocabulary

- Receiving knowledge from the literature on education through others

- Input is valued from scientists and/or engineers who have practiced PBL

- A sage whose input is valued signifies a more formal operation of meetings

Factors that influence the desire to participate in the discussion

- Wanting to work closely with students and really know what they are learning

- Having caring attitude and close relationships with students prompts reflection and discussion about LTA

- Student profile at this institution (non-traditional background and low academic profile) prompts discussion about LTA

- Sharing modules with others prompts discussion about LTA and how to improve student experience

- Owning modules allows one to control LTA methods

- Lacking knowledge on education literature relative to others can lead to holding back and not joining conversation

- Being skeptical of the literature on education

- Committee meetings prompt discussion about LTA

These themes reflect one important stage in this change-effort where participants were expanding the way they conceptualize learning and teaching. 


\section{Textural summary}

During the textural phase of the study, we were trying to assess raw pre-reflective experience to the greatest extent possible - meaning we wanted to know what participants had felt viscerally, rather than what they later thought about the experience. In assessing the texture of what happened, we came to realize that informal discussions of learning, teaching, and assessment (LTA) arose daily among staff in this programme. Lecturers would arrive for coffee or lunch without prior arrangement, sit beside each other and let their conversation drift across LTA issues. Others would join the conversation and, depending on their own interests, steer conversation towards or away from LTA. The participants in our study found these conversations interesting and enjoyable - a way to enrich the experience of teaching and deepen their friendships. They appreciated the formal and informal meetings, finding even the heated debates interesting and rewarding.

There's a group of us who have coffee together regularly... we sit down and we generally do talk about these issues. Nine times out of ten we are talking about something to do with teaching.

The formal meetings were described by those in regular attendance as:

a regular focal point that kind of punctuated what was really much more of an ongoing dialogue between all of us who were teaching together.

The high frequency of formal and informal encounters allowed ideas to be developed iteratively. Participants observed their students in class and reflected on their experiences. Over coffee and lunch, as well as periodic formal meetings, they would offer their thoughts for discussion. After receiving feedback from peers, they would reflect individually and then share realisations. Those who had read literature on LTA would pass established principles on to others, so all were exposed to current research. They developed a shared vocabulary (of techniques, theories, and terminologies) regarding teaching and learning. These discussions helped expand individuals' conceptualizations of teaching. Since such issues, discussed in formal meetings of this FLC, were elaborated upon during coffee and lunch in the staff canteen, this small group continually engaged a much larger audience. They also tried to model effective behavior for students. Discussion helped individual tutors confront doubts and address barriers to change. Such doubts and barriers included: concerns that less content would be delivered as more time was allocated to student project work, how to achieve fairness in grading, how to provide helpful formative feedback in a timely fashion, how to deal with free-loading students, their own past discomfort with group work, and their belief that many engineering students chose the major to avoid interacting with others.

During meetings, participants influenced each other and then, in a multidirectional exchange, persuaded each other to think differently about LTA. One person would carry another along, only to be the person who was carried at another time. Members played different roles in the group, because their areas of concern and their commitment to PBL varied widely. Formal and informal meetings were used by the teaching fellow to evangelize concepts, promote specific techniques, and convince others to adopt PBL. The group put PBL techniques into action themselves, and discovered that they quite enjoyed the group decision-making process that they were 
asking of their students. When the learning development officer was present, his input was valued and respected.

\section{Structural summary}

Regarding how tutors experienced the group, participants described feeling comfortable discussing contentious issues with colleagues. Across the board, participants trusted each other, regarded each other as friends, and sought out interesting conversations about what they were teaching. Participants looked forward to meetings - to hearing and offering new ideas and anecdotes regarding PBL. They considered such conversations as fun, rewarding ways to learn. Several participants wanted to offer these similarly rewarding discussions and learning experiences to their students, via PBL.

I would say it was enjoyable, challenging, and reassuring... hanging out and chatting with them.... They were nice people to spend time with... it didn't feel like a chore at all. It was kind of a social high point of the working week.

Another described feeling highly motivated to participate and wanting to be better at what he does:

That's a nice feeling. Like I do particularly enjoy the conversations that we all have. I think it's great that we all get on so well together and that's nice. I usually get the same thing from [doing collaborative] research, where there is groups of us working together. So maybe that's the part that I like, working with other people.

Conversations increased their shared sense of purpose, which promoted more good feelings:

there is a kind of, almost a group think, or a collective consciousness doing all this. And now it works well and makes here a nicer place to work in.

He characterised their brand of "group think" and its reach in the programme:

Don't answer the questions directly. That's kind of the big thing I suppose - make the students try and figure out themselves....We have to strike a balance there ... between some bit of problem-based learning and some bit of guidance learning. ...You lead them down a little bit of the pathway and let them go find the rest themselves, and you have to judge how far down the paths you might go. Depending on the students you have it varies. ... And at the moment the leadership here would be bought into the whole idea of problem-based learning and it's, it's the culture. It's in the culture of education at the moment.

There was not, however, perfect agreement regarding pedagogy. One participant explained that he had doubts about PBL and felt he lacked knowledge of LTA literature. This prompted him to avoid formal discussions of pedagogy while nevertheless engaging in informal talks regularly. He got drawn in during coffee time, nevertheless:

[The teaching fellow] has been sort of reading literature and I suppose disseminating this literature enthusiastically out at coffee time... we don't necessarily have to read these journal papers ourselves; we'd argue them. 
He's bouncing his opinions off us and I suppose they become more robust by being buffeted by our opinions, you know, and vice versa.

In fact, several participants expressed doubts, but these usually had to do with specific aspects of PBL. Misgivings also arose in cases where they perceived educational research to be too subjective and at odds with their engineering epistemologies that tend to be more positivist. They also cited contradictory findings reported in various studies as a cause for concern. To them, findings in education research seemed much less clear and reliable than findings in engineering. This negatively influenced some participants' receptiveness to apply pedagogical theories. Despite these misgivings, they all held a clear sense of the value of learning from STEM educators within this institution who had experience applying PBL. They were interested to hear from educators who had implemented the techniques, and they valued input from their learning development officer who had technical experience and knowledge of the literature, as well as understanding of their local context.

he was certainly able to give answers - both from his own experience and from the literature - about the sort of things we were asking him.

They also sensed they were passing their expanded conceptualizations and skills to others outside the group:

So, I said, in future all of my notes are going on line and we'll just talk about them in class. So, in that sense, moving that along, I've been working with people who are maybe of an older generation and helping them along with that. And the person this year who I've helped along a lot-because I think he was a bit scattered up to this point now, because I'm sharing a lab with him briefly this year-I think next year he could go into the lab and he'll end up saying 'oh it's all there.' It's all written out, no lab sheets, no winging it and a proper way of assessing this thing, which you can stand up.

Overall, several factors motivated participants to engage in this peer learning group, including a sense of camaraderie and a desire to reach their student population most effectively. Ownership of modules (i.e., being seen as the leader of a particular course or subject area and being the primary person responsible for its delivery) provided participants a high level of freedom to implement LTA principles. Sharing modules with other lecturers - through team teaching and/or delivering modules in collaboration with other teachers - prompted discussion, as did programme committee meetings, and planning for an upcoming accreditation visit.

\section{Composite summary}

Regarding the essential essence of this group's learning experience, participants had encountered a broad spectrum of student ability and motivation. Being assigned to teach 18-20 hours per week, these lecturers often found themselves in the laboratory tutoring small groups, which led them to observe students closely and get to know them. Such activity fostered reflection and a general desire to improve student engagement and performance and, for many participants, to facilitate better teamwork and collaborative learning practices among students.

Challenges encountered in the classroom also got voiced in the staff canteen, where members of the teaching staff typically go for coffee and lunch. Impromptu 
discussion occurred at each other's staff desks within shared offices, or in the course of team-teaching. Participants in this study reflected a range of conceptualisations of teaching, with some valuing group-based learning more than others. Levels of familiarity with LTA literature also varied. Yet all this variety was valued:

You definitely get a better understanding by talking it through with somebody else. ... It kind of clarifies your own position. That's what I find is one of the key things. You're getting other people's opinions as wellit's also influencing you.

Those who enthusiastically implemented PBL in their own classrooms particularly welcomed the formal monthly gatherings of this small group, where the agenda usually stuck to pedagogical issues. The formal meeting provided a sheltered space for discussing how to facilitate PBL. This protection kept them from rehashing the debate over the value of PBL that was occurring in the staff canteen at the time. Since some members of their group still had strong hesitation about PBL, they found plenty of room for debate, both outside and inside the sheltered meetings. Such variety, within an atmosphere of trust and lack of judgment, led to healthy debate of prickly issues. Members challenged each other and acted as sounding boards for ideas.

We're all quite friendly, as well. So we would socialize a bit together. And I think that helps... especially if you're discussing something that's potentially a bit contentious.

Due to their prior participation in post-graduate courses on learning and teaching, more than half the group shared a common vocabulary regarding pedagogy that they spread to the others.

[The teaching fellow] has run with this [along with two others who took the Post-Graduate Certificate in Learning and Teaching] with him. [One] sits beside him in the office, so they're going to share naturally. And [the other] is relatively newer - a new member of staff.... They'd be the main ones [leading this change].'

These core members of the group, along with the learning development officer, were seen as central to the group's progress and success. They were most committed to student-centered learning and most enthusiastic about the meetings, describing them as energizing and intellectually stimulating.

Our discussions are always interesting. So they're enjoyable. That's sometimes why they go on so long.

Ultimately, the group practiced the same principles of self-directed learning and metacognition that they hoped to instil in their students. This statement reflects the participant's deep reflection on the subject:

It's partly the reason why I think group-based learning techniques work, because what we're doing when we're having these chats, that's group-based learning.... For us it's trying to develop... an understanding of how to teach better. But for our students it's about how to learn some difficult concepts. 
Although many participants were sceptical of the literature on LTA, reports of this literature from the learning development officer were valued and accepted, because he was an experienced PBL practitioner who could relate LTA theory to examples from practice. The teaching fellow encouraged greater adoption of PBL and helped move the discussion from improving modules to improving the overall programme. He focused the conversation and consistently championed the cause.

[The teaching fellow] has continued to be a driver of conversations. It's periodically about different things to do with group learning.... He has continued to be a champion within the School, for placing it on the agenda of the School management and making sure the resources are put in place to actually facilitate this style of teaching.

In this particular case, having a visible and enthusiastic champion surrounded by engaged and supportive colleagues and guided by an experienced advisor helped sway opinion. Together this group helped convince themselves and others to make uncomfortable changes. The group gathered momentum and cultivated support over time.

\section{Phase 3: situating findings in the literature and comparing methods}

In the third phase of the study, we situated the findings from Phase 1 and 2 in the literature, to assess the degree to which our results fit existing theories and models. Then we did comparative analysis of the two methods to discern how well they fit our dataset. We compared what we had learned using each of the two methods above.

\section{Comparing literature}

In this study, camaraderie helped participants implement new techniques and address challenges and doubts as they arose. Theories of self-regulated learning were supported by participants' descriptions. For instance, this small group regulated its own work in ways promoted in literature on PBL. We assess each set of theories identified in the literature review:

\section{Conceptions of learning}

Transcripts provided evidence of a shift over time in the conceptualizations of the teaching staff, to emphasize students' learning over simple content delivery (Barrie, 2007; Degago \& Kaino, 2015). Participants described changing their own and others' conceptualization of teaching from delivering content to becoming 'agents for change' who help students develop new skills and understandings. In keeping with Bruffee (1999), this group described conversation, reflection, a shift of hierarchy, application of research, implementation of new pedagogies and new models of dialogue, and even the construction of a new physical space (in this case, a new laboratory equipped for group PBL and dedicated specifically to this programme). Participants wanted to balance learning-oriented and content-oriented approaches; this shows a level of awareness that Degago and Kaino (2015) say requires mastery of all levels depicted in Figure 1. Such a shift in conceptualizations was evident in many transcripts, and also succinctly stated in the visiting scholar's written report:

My [prior] efforts at teaching have been directed at knowing the material very well and presenting it as clearly as possible.... Good group work is the subject of what I learned in [the electrical engineering programme and] most of what I learned regarding assessment of learning in the group-based environment occurred during 
tutoring activities in [that programme]....Many of those topics [studied for the Post Graduate Certificate in learning and teaching and implemented within this engineering programme] have strongly affected the way I think about teaching and learning, and will hopefully make me a better teacher in the future. The most significant and useful of those ideas for me are the concepts of constructive alignment of intended learning outcomes (ILOs) with learning activities and assessment tasks in curriculum (module) design, the use of formative assessment, and criterion-referenced summative assessment.

\section{Behavioral change}

In this FLC, those who completed the LTA courses were seen as leaders in shifting teachers' conceptualizations toward the student (Kember \& Kwan, 2000). Together, this core group provided the larger group with deeper understanding of what such a change "means and how it can be accomplished" (Gardner, 2014, p. 110). A spirit of collaboration and a culture of discussion in the canteen helped them motivate each other, including reluctant peers, to implement and sustain new teaching practices. Reflection (at the individual and group level) was important in helping move individual teachers from pre-contemplation to action (McKenna, Yalvac, \& Light, 2009; Prochaska, Redding, \& Evers 2002).

This peer-learning group helped achieve the balance of readiness and support necessary to help members implement change (Sanford \& Adelson, 1962). Participants developed new skills - over time and with support of peers and advice from an administrator - to overcome daunting challenges. Enjoyment of, and satisfaction with, peer-to-peer dialogue encouraged participants to identify and confront their own doubts and insecurities. Consistent with Blumenfield, Kempler, and Krajcik (2006), participants accrued motivational benefits by working as a group. Enjoyment of collaboration seemed to counterbalance the effort needed to begin implementing changes and to master new teaching techniques (Tweddell, Clark, \& Nelson, 2016; Savin-Baden, 2008). In this case, the new teaching techniques being implemented involved group-based projects and increasingly open-ended assignments, which were scaffolded with guidance on working in groups, and were provided alongside formative feedback and continuous assessment. Like the pharmacy teachers interviewed by Tweddell, Clark, and Nelson (2016), participants in this FLC felt greater enjoyment in teaching and perceived that student engagement increased. Interviewees articulated a shared ethos of student engagement and pride in serving diverse students. They viewed themselves as part of a grassroots change effort within a faculty deeply committed to students and students' learning. Of central importance was group members' passion for helping their students succeed (Hobson \& Morrison-Saunders, 2013).

Leadership is crucial to helping people change their behaviours and to help move them from being 'unconsciously incompetent to (un)consciously competent'. When most or all participants in a group are unwilling to change, it is very unlikely to happen. Real change is also unlikely when none of the people in a group are familiar with and have a clear conception of the change needed.

\section{Change management and grassroots leadership}

This FLC achieved results based on high-quality knowledge and input and high engagement of the group of participants. Achieving buy-in is critical. Results here were consistent with Fullan's (2001) book titled "Leading in a Culture of Change." In this FLC, the champion gave attention to all the various aspects of leadership for change defined by Fullan (2001). He projected energy, hope, and enthusiasm and the worked to create and share knowledge, understand change, build relationships, achieve coherence, 
and behave with moral purpose.

This change effort successfully combined bottom-up and top-down approaches (Kezar \& Lester, 2011) because the institution's center for learning and teaching and the college's learning development officer both helped create "a climate for change" while the fellow/champion helped galvanize "a change agenda through an organic process of collaborating with colleagues" (Perry, 2014, p. 164).

In this project, we sought to understand why participants viewed this as a grassroots effort when it had been supported from above with awards and capacity building programmes. Consistent with Hofmeyer et al (2015), grassroots aspects of this change included: (1) understanding the existing culture; growing the voice and visibility of the group and its cause; (2) developing ability to influence direction of the programme; (3) learning leadership skills together; and (4) changing the culture. In this case, collective learning occurred among a small group of teachers about their aims and curriculum and collective learning was also evident across the entire academic department in the form of a shared philosophy, vision, and mission that was codified into programme documents and implemented in practice (Edintaite, 2012).

Also aligned with our review of literature on grassroots leadership, statements by FLC participants reflected deep collegiality and the "congenial and sympathetic company of scholars in which friendships, good conversation, and mutual aid can flourish" that Bowen and Schuster (1986, p. 55) described as fundamental to change. Results highlighted the importance of the individual champion who advocates change, provides a vision, promotes new approaches, and builds momentum and support among colleagues (Black \& Gregersen, 2013). The sense of equality among peers aided the champion's efforts in community building, conceptualization, persuasion, empathy, stewardship, and commitment to the growth of others (Spears, 1998) and it reflected the type of servant leadership defined by Greenleaf (1977).

Nevertheless, our research also highlighted the importance of policies and capacity-building programmes provided by the Institute. Several participants had earned qualifications in learning and teaching. The fellow/champion had taken such courses voluntarily, and newer members of the staff had done so as a policy requirement. By taking courses on learning and teaching, tutors had developed common understanding. They had accrued a shared vocabulary regarding pedagogy, curriculum design, learning theories, feedback, and assessment. The Institute, in backing its policies with education programmes as well as grant and fellowship programmes, helped foster and support change at the grassroots level.

Interestingly, however, participants felt a lack of support from above. Most of them had not perceived the various forms of support that were actually in play. For instance, the learning and teaching centre had provide the $€ 2000$ fellowship stipend that precipitated these monthly meetings. Granting fellowships was a way that the Centre was encouraging the application of theories and practices it promoted, even though FLC participants said that teachers within the Centre often used traditional lecturing methods rather than hands-on student-centred approaches when delivering workshops and modules to them. Despite such flaws, the awarding of this fellowship was aligned with Walker and Laurence's (2005) recommendation to support the activities of organizing, planning meetings, researching and publicizing issues, and educating stakeholders about "appropriate actions to take" (p. 268). The award encouraged the fellow to take such a role. Specific ways this scenario fit recommendations by Walker and Laurence included having: (1) a close colleague who had read these theories see their relevance and champion their use; (2) a group of people who like working together; and (3) the impetus to schedule recurring meetings. 
Despite being blessied from above, implementation was successful very specifically because the participants embraced this change as their own. They did not see it as an activity that had been mandated; they saw it as fun and as growing out of their own interactions with colleagues and students. Those most prone to dissent specifically described this as a grassroots effort. Although the change was clearly in line with desires of upper administrators, even those resisting centralization of authority in this historically decentralized organization were willing to participate in discussions led by familiar colleagues. They were willing to discuss new theories and research that others brought to the table, particularly when relevant examples were provided from the local context.

\section{Faculty Learning Communities}

This case reflects clear alignment with Edintaite's (2012) desirable elements: (1) individual learning by all teachers regarding subjects they teach, (2) collective learning among small groups of teachers about their aims and curriculum, and (3) collective learning across the entire academic department to create shared philosophy, vision, and mission. Even after the formal FLC meetings ended, one participant sensed an effect:
Although we don't still meet in that formal way the fact that we did, I
think, has carried through into my friendship and working relationship with
... quite a group of people, I suppose, who've been involved in some way
in this dialogue over the course of a few years. But in particular there's
kind of a handful of people that I would look to as my sort of 'community
of support' for teaching project-based learning and group-based learning.

Unlike the NSF-funded study (Ingram, Litzler, Margherio, \& Williams, 2017), there was no need to re-negotiate the promises they made grantors. Nevertheless, this FLC still had to set boundaries for the discussion and create a vision for itself. It appears that, in order to convince managers and colleagues to support the changes with new policies, streams of funding, and a new PBL classroom, the FLC did shape some form of communication strategy and determine key messages to communicate outside the FLC. Wicks, Craft, Mason, Gritter, and Bolding (2015) recommend that cross-disciplinary FLCs can be highly effective in spurring change, this group was composed mostly of engineering educators, with a physicist as the advisor. Yet, they drew heavily from educational theory because the advisor/sage, teaching fellow/champion, two younger staff, and the visiting professor all completed degrees of some sort learning and teaching.

\section{Self-regulated learning in groups}

As highlighted by one of the FLC participants, this group essentially implemented the same Problem-Based Learning process they were teaching their students. They defined a project themselves, broke it into components and developed a strategy for realizing it. In the process, they integrated, generated, and shared knowledge with each other (Fong, 2003). They accessed supportive resources and evaluated their own success through a process of reflection and metacognitive awareness (Järvelä et al, 2010; McKenna et al, 2009; Volet, Vauras, \& Salonen, 2009). The group confronted doubts and frustrations together, in a safe environment, undergirded by a sense of collegiality and professional respect, where frank discussion was encouraged and innovative approaches proposed, tested, and assessed.

Group-based, project-driven learning is a recognized way to build students' ability to self-direct their learning. In a student-centered PBL environment, the student: 
guides the learning process; learns disciplinary content while concurrently developing learning skills; and stitches new ideas into his or her existing frames of reference (Duffy $\&$ Bowe, 2010). The problem or project provides the impetus to learn and to explore new content. The teacher provides frequent, formative feedback (regarding techniques, knowledge, and approach).

FLC participants' descriptions lend support to emerging literature on collaborative learning and Socially Shared Metacognitive Regulation (SSMR). Consistent with the findings of Järvelä, Volet, and Järvenoja (2010), "when individuals communicate their assumptions, members can add to, continue, agree, or disagree with each other's explanations, allowing the group to construct shared assumptions, and a more comprehensive and accurate interpretation of their situated activity" (p. 23).

This study underscores the importance of social processes in motivation and change. It provides a case study example of "enacted, dynamic, and social processes" (Järvelä, Volet, \& Järvenoja, 2010, p. 19) and the co-creation of an environment that encouraged and motivated participation. This group implemented crucial self-regulation behaviors of planning, monitoring, and engagement and the type of affirmative "socioemotional interactions and collaboration" (Rogat \& Linnenbrink-Garcia, 2011, p. $375)$ that seems to facilitate successful social regulation.

High-quality SSMR has been associated with cases where the tutors modeled metacognitive thinking for students and prompted them to consider their own ways of thinking (de Backer, van Keer, and Valcke, 2015). Here, participants reflected on their own thinking and regulated their collective learning. They modeled metacognitive thinking while meeting with groups and by creating a video that introduced students to the metacognitive practices underlying self-directed learning. As a group of teachers learning together, they implemented desirable SSMR techniques and learned to guide student groups in doing the same.

Over time, FLC members became more skillful and purposeful in applying metacognition at the individual and group levels and in modeling such behavior for their students. In this case, collaboration and positive emotional interactions helped the individuals overcome deep-seated doubts as well as frustrations and anxiety they encountered in making the change, assigning group work, tutoring peer-learning groups, and providing effective feedback.

\section{Comparing methods}

In the process of comparing research methods, we found that both yielded insight toward understanding: What was it like to be part of a learning group focused on tangible change toward student-centered learning? Yet, the method and perspective adopted for each Phase filtered and coloured what we saw. The grounded theory phase adopted a leadership perspective and found that - although institutional policy, leadership, and capacity building programmes were essential - these were only effective when buy-in from a large number of staff was achieved. The phenomenological phase provided much more detail about how staff members became motivated to change. An essential finding of this phase was that for dissenters and skeptics, it was important to feel their colleagues had launched this movement, that their justification was sound, and that it fit their ethos.

The comparison of techniques detailed below allowed us to answer the two following questions as well: (1) To what extents do the research methods of grounded theory and phenomenology fit our data and yield relevant and useful findings? and (2) What implications does our study hold for research? 


\section{Phase 1: grounded theory}

In retrospect, the grounded theory method used in Phase 1 provided a much more expeditious way to study the data, summarize results, and distill findings. Grounded theory is longer established and better recognized as a research method than phenomenology. There is a higher level of agreement among scholars as to what constitutes grounded theory, although there is also a large degree of flexibility in approaches.

In Phase 1, we conducted open, axial and structural coding of the interviews provided by the administrator and two others to identify specific themes and group them into categories. We used well-tested and tried methods for conducting open, axial and structural coding. We reviewed many different scholars' recommendations for grounded theory analysis (Creswell, 2013; Denzin \& Lincoln, 2011; Savin-Baden \& Major, 2013; Strauss \& Corbin, 1994), and we did not find huge disagreement among them. We used template analysis to support this process because it provides an easy way to organize data manually and to sort themes into categories. Moreover, it is appropriate to the process of grounded theory (King, 2004). We reviewed all transcripts, coding them in relation to the template and adjusting the template as needed to reflect what we were hearing from the whole set of participants. In this process, the initial themes were grouped into clusters. They were also consolidated, eliminated, or expanded as needed to align with the entire pool of data.

The final template identifies relationships among themes and categories. Organizing the data in this way facilitated development of graphic models. Early models (e.g., Figure 2) were less developed than our final model (Figure 3). Subsequent conference papers, presentations, and work conducted in Phases 2 and 3 helped us clarify and add elements to the final model (Figure 3).

\section{Phase 2: phenomenology}

Phenomenological methods, used in Phase 2, yielded richer and more nuanced understandings of our data. Yet, phenomenology was extremely difficult to apply on this particular dataset. We read many books describing different variants of phenomenological analysis - from early studies that followed the methods without using the term (Lynch, 1960) to highly interpretive methods (van Manen, 1990) to highly descriptive (Giorgi, 2009). Each scholar identified methods that were very specific, yet very different from each of the others. There was disagreement on many questions we had, such as whether or not to use member checks. Regarding this topic, Giorgi (2009) vehemently opposed the use of member checks since participants are not privy to the full set of data and have not been part of the empirical analysis. At the other extreme, Moustakas' (1994) and Smith (1994) recommended viewing participants as co-researchers, as we have, and including them in the research process via member checking.

Based on our reading of these disagreements and of Giorgi (2009), we realized how important it was to align all elements of the method and process we chose so that there would be consistency within the study's internal logic and alignment with its overarching philosophy. We selected Moustakas' (1994) method for phenomenological analysis because it provided a clear road map with internal logic that we could follow. It was also consistent with our view of participants as co-constructors of the phenomenon of study. Across the course of the study we continually questioned to what degree Moustakas' method facilitated understanding of this particular issue. We found that for a phenomenon that involves metacognition - a characteristic at the very core of both PBL and self-directed learning-reflection is an inherent component. Bracketing out 
statements of reflection, in this case, meant losing much valuable data. We thus excluded many important and informative statements involving opinion and reflection such as, this one about PBL:

it has some very, very positive things. It makes the students take ownership of their own learning.

This statement was one of many riddled with reflection and opinion, yet it also held a key to understanding the type of conceptual shift we were aiming to pinpoint among the teachers in the group.

In trying to be true to Moustakas' (1994) process, our initial work in Phase 2 focused expressly on emotive aspects of the environment (e.g., feelings, frustrations, joys, sensory input). As a result, using this method limited our ability to assess conceptual shifts described by participants. Although we found Moustakas' definitions to be very clear and helpful in conducting work, we came to realize that discerning textural aspects from structural ones is difficult even where data fit the model very well. In this case, however, the data did not fit the model well due to the time lapse between events and interviews. This meant most of the data were reflective in nature, and that participants had formed a range of opinions about their experience. This made locating descriptions of raw experience extremely difficult and made separating them away from reflections and opinions even more so.

After the textural, structural, and composite statements had been made, relevant literature was identified and participant quotes were added to the summary descriptions. We did this to provide readers with evidence to support our summaries and our interpretations.

Phase 3: situating findings in the literature and comparing methods

Phase 3 was extremely helpful in drawing insights. Situating findings in the literature helped us explain the paradox between top-down and bottom-up leadership models; it helped us recognize that some members of the group will be more convinced by bottom-up than top-down approaches, and vice versa. Using both can help convince a larger crowd and draw more people into the change initiative. The overall goal here, after all, was to get teachers to change their behaviours and implement new techniques. To do this, the literature indicated, it would also be necessary to change their conceptualizations (Kember \& Kwan, 2000). In comparing methods, we found that our phenomenological techniques discarded many of the statements related to conceptualizations because these are inherently metacognitive rather than relating to description of experience. Thus, to answer this particular question, the phenomenological method we used was not as helpful as the grounded theory method.

In the final stages of this project, we were asked by reviewers: To what extent could change agents deliberately influence the content or type of learning - can they do more than providing capacity building programmes? Our answer is yes, leaders can help create a culture of mutual trust and understanding, of collegiality, a culture where ideas are valued and openly discussed (Bowen \& Schuster, 1986). Leaders can project a sense of energy, hope, and enthusiasm (Fullan, 2001). To be effective, they must work to build relationships, create and share knowledge, understand change, behave with moral purpose, and achieve coherence (Fullan, 2001).

\section{Conclusions}

In this conclusion, we identify implications for research and for practice. We also 
identify limitations of this study — namely the small sample size and having highly collegial context that may not be transferrable to the majority of other settings. Despite the high level of camaraderie, however, there was also a high and clear level of disagreement with PBL being voiced across the staff. That level of discord made it necessary to hold the FLC meetings in a protected environment elsewhere. It seems that discussions originating at FLC meetings rather happily reverberated into the on-site staff canteen during coffee and lunch, however.

\section{Implications for research}

Nearing the end of this project, we identified implications and directions for future research. We would still like to know more about when and how teachers' conceptions change, as well as when and how students' conceptions (i.e., epistemologies) change. In this study, we found staff members' growth and learning was a result of the interaction in the group, and an outcome of self-regulated learning.

\section{Implications for practice}

In discussing implications for practice, we focus on how leaders might use this example to foster and support similar change in their organizations. Our discussion involves the structure of the group at this institution along with strategies for achieving buy-in from individual faculty members. Analysis of interviews conducted in 2012 indicated members of this group naturally gravitated to discussing LTA issues. They did so in their shared offices and over lunch and coffee in the staff canteen. The combination of informal daily chats and focused monthly meetings proved invaluable. Holding the monthly discussions in a location off-site helped frame the conversation. Physical distance helped the teaching fellow shape the topic of discussion and keep the focus on how to implement new techniques. This champion avoided, or 'framed out' extraneous discussion of whether, or not, such changes were merited. Those conversations were frequent discussion among programme faculty at the time and he saw them as distracting the teachers from considering how to move ahead. Although the site was located off their beaten path, most participants were unable to distinguish memories of the formal meetings from the regular informal chats because they tended to discuss such topics daily in their staff canteen, offices, and classrooms. Importantly, however, this small group managed to successfully confront doubts, debate a variety of approaches, identify merits of each, address concerns, implement and test various applications between meetings, and compare results over lunch and at subsequent meetings.

Participation in small groups discussions enabled both a conceptual and a curricular shift across the department. In a relatively short period of time, the group expanded it repertoire of group-based projects and pushed colleagues in their programme to formally adopt PBL and codify PBL within accreditation documents. These conversations proved fruitful in helping teachers apply PBL in their classrooms and advocate change at the programme level. These teachers needed convincing rationale as well as help in addressing challenges and doubts. This grassroots effort implemented PBL approaches, and working together provided these tutors with inspiration and confidence to persevere against challenges and perceived resistance.

These elements have helped create the ethos that many faculty members referenced in their interviews. One aspect of that ethos is the value the community places on industry perspectives and professional accreditation. In fact, all participants noted what they were doing was aligned with goals of their accrediting body. So, after testing new approaches, they brought proposals to the larger programme faculty to discuss and adopt. Thus, innovations discussed in FLC meetings and tested in practice 
were subsequently advocated during formal programme meetings.

During the immediate accreditation cycle, members of the peer-learning group skillfully explained to their colleagues how the changes they desired would enhance their standing with regard to accreditation. Core members of the group used the pending accreditation visit as reason to address requirements with PBL pedagogies. Existing culture helped make this change possible, in concert with relatively new capacitybuilding programs.

Overall, the formation of a peer-learning group helped equip the electrical engineering educators in our study to implement innovative practices, despite the challenges and doubts they were encountering. The sense of collegiality, camaraderie, and encouragement participants found in this group convinced them to stick with the effort. Participation helped individuals transform their modules, work together to spearhead programme-wide change, and even advocate for college-wide change by delivering workshops and seminars outside their programme. Formal meetings were effective because the group had a shared project (developing ways to provide fair assessment and timely feedback) around which to focus their efforts and discussions. Their shared sense of purpose, coupled with a loosely defined agenda kept the group focused and on-task.

Lasting change in engineering education at this institution has been due to the perseverance of individuals who are steadfastly dedicated to reaching students in more effective ways. The existence of the institution's Learning, Teaching and Technology Centre (LTTC) that delivers Post Graduate programs in learning and teaching - and the LTTC's ability to infuse values and disseminate information on specific pedagogieswas instrumental in sowing the seeds of change. Calls for change coming from practitioners, researchers, and accrediting bodies encouraged people in this programme to change. Teachers there started changing one by one, most after taking modules in learning and teaching. The formation of a faculty peer-learning group helped equip educators there to implement innovative (yet challenging) practices in their classrooms. The sense of camaraderie and support they found in this group convinced them to stick with their efforts even in difficult times. Nevertheless, the champion of this effort asserts that having even greater support - and a clearer vision for a new curriculum in place at the beginning - would have helped push success further. He and his peers are helping build such a vision for others.

In the final stages of this project, we were also asked: How successful would the group have been in convincing other staff and the administration to adopt pedagogical shifts and policy changes if they existed in a different cultural context in which this sort of connected and supportive environment did not exist? Our data suggest that this change took hold widely because staff members found their social interactions to be fun and interesting and they were happily willing to focus their discussion on how to help students learn more effectively. Leaders can promote change by promoting enjoyable personal interactions and a culture that values student learning. They can provide a system to build capacity and support efforts in the desired direction. Here, even participants who objected to receiving direction from above were willing to implement change, because they saw it as something of value to their students and important to colleagues they esteemed. However, it is worth noting that participants did not associate the larger Learning and Teaching movement with any specific person in the administration. They saw it as consistent with the institution's ethos and mission, but in 2010-2013 interviews they could not describe what strategic direction the central administration was taking other than building a new campus. This institution was highly de-centralized and spread across many buildings though the city. They had, at the time, 
little to no understanding of the institution's organization chart or its chain of command beyond the College level. They also did not know who supported or funded the LTTC, as this appeared to be in constant flux.

Because we also have been asked: What will the results mean for future change strategies, especially for change processes where not all staff are positive? we offer some thoughts on relative levels of formality and informality that facilitated successful transformation at this institution. This project began with the intention of studying the formal learning group that lasted for one academic year. However, what became clear during the course of the project was that a much less formal and less defined group of staff met (and continues to meet) on an ongoing basis in the staff cafeteria. We came to understand that this informal exchange of knowledge was at least as important as the formal group. This informal meeting arrangement became the main setting for participants to learn from others in the group. Yet 'membership' in this FCL was hard to define; its edges were blurred. Who attended was not completely clear. Yet descriptions of these FLC meetings influenced many of the stories featured in the interviews. An equally important component of the programme's transformation was the shared canteen where staff members frequently gathered to socialize and share ideas. Frequent communication, camaraderie, and collegiality have been part of the organizational culture. Social spaces and social dynamics of this sort are worth developing elsewhere; they can help empower individuals to overcome fear and doubt, and change their conceptualisations and their behaviours in ways that enhance their teaching.

\section{References}

Åkerlind, G. S. (2003). Growing and developing as a university teacher--variation in meaning. Studies in higher education, 28(4), 375-390.

Alonso, F. G., Soria, S. L., \& Gozalo, J. C. (1991). Comparing two methodologies for crop area estimation in Spain using Landsat ${ }^{\mathrm{TM}}$ images and ground-gathered data. Remote Sensing of Environment, 35(1), 29-35.

Barrie, S. C. (2007). A conceptual framework for the teaching and learning of generic graduate attributes. Studies in higher education, 32(4), 439-458.

Barrows, H. (1994). Practice based learning: Problem based learning applied to medical education. Spingfield, Illinois: Southern Illinois School of Medicine.

Birnbaum, R. (1988). How colleges work: The cybernetics of academic organization and leadership. San Francisco: Jossey-Bass.

Black, J. S., \& Gregersen, H. (2013). It starts with one: Changing individuals changes organizations. Pearson Education.

Bergeron, F., Buteau, C., \& Raymond, L. (1991). Identification of strategic information systems opportunities: applying and comparing two methodologies. MiS Quarterly, 89-103.

Berggren, K. F., Brodeur, D., Crawley, E. F., Ingemarsson, I., Litant, W. T., Malmqvist, J., \& Östlund, S. (2003). CDIO: An international initiative for reforming engineering education. World Transactions on Engineering and Technology Education, 2(1), 49-52.

Bowe, B. and Cowan, J. (2004), A comparative evaluation of problem-based learning in physics: A lecture-based course and a problem-based course, in Challenging Research into Problem-based Learning, edited by Savin-Baden, M. and Wilkie, K., SHRE / Open University Press, pg 161-173.

Bowe, B. (2007), Managing the Change from Traditional Teaching to Problem-based Learning in Physics Education, in Management of Change: Implementation of 
Problem Based and Project Based Learning in Engineering, edited by A. Kolmos, and E. de Graff, Rotterdam, Sense Publications.

Bowen, H. R., \& Schuster, J. H. (1986). American professors: A national resource imperiled. Oxford University Press.

Bruffee, K. A. (1999). Collaborative learning: Higher education, interdependence, and the authority of knowledge. Johns Hopkins University Press.

Campbell, D. T., \& Fiske, D. W. (1959). Convergent and discriminant validation by the multitrait-multimethod matrix. Psychological bulletin, 56(2), 81.

Chance, S. M., Duffy, G., Bowe, B., Murphy, M., \& Duggan, T. (2013). A model for transforming engineering education through group learning. Proceedings of the International Conference on Engineering and Product Design Education. Dublin, Ireland.

Charmaz, K. (2014). Constructing grounded theory. Sage.

Creswell, J. W. (2013). Qualitative inquiry and research design: Choosing among five traditions. ( $3^{\text {rd }}$ ed.). Thousand Oaks, CA: Sage.

Creswell, J. W. (2007). Research design: Qualitative, quantitative and mixed methods approaches. ( $2^{\text {nd }}$ ed.) London: Sage.

Creswell, J. W. (2018). Research design: Qualitative, quantitative and mixed methods approaches. ( th $^{\text {th }}$ ed.). Los Angeles, CA: Sage.

Creswell, J. W., \& Miller, D. L. (2000). Determining validity in qualitative inquiry. Theory into practice, 39(3), 124-130.

Davis, N. T., \& Callihan, L. P. (2013). Integral Methodological Pluralism in Science Education Research: Valuing Multiple Perspectives. Cultural Studies of Science Education, 8(3), 505-516.

De Backer, L., Van Keer, H., \& Valcke, M. (2015). Exploring evolutions in reciprocal peer tutoring groups' socially shared metacognitive regulation and identifying its metacognitive correlates. Learning and Instruction, 38, 63-78.

Degago, A. T., \& Kaino, L. M. (2015). Towards student-centred conceptions of teaching: the case of four Ethiopian universities. Teaching in Higher Education, 20(5), 493-505. doi:10.1080/13562517.2015.1020779

Denzin, N. K., \& Lincoln, Y. S. (Eds.). (1994). Handbook of qualitative research. Thousand Oaks, CA, US: Sage Publications, Inc.

Denzin, N. K., \& Lincoln, Y. S. (2011). The Sage handbook of qualitative research. Sage Publications.

Duffy, G., \& Bowe, B. (2010). A framework to develop lifelong learning and transferable skills in an engineering programme, presented at the 3rd International Symposium for Engineering Education, University College Cork.

Dukes, S. (1984). Phenomenological methodology in the human sciences. Journal of Religion and Health, 23(3), 197-203.

Eastman, C. M., McCracken, W. M., \& Newstetter, W. C. (2001). Design knowing and learning : cognition in design education. Oxford: Elsevier Science.

Edintaite, G. (2012). University and non-university teachers' organizational learning. Social Sciences (1392-0758), 76(2), 51-60. doi:10.5755/j01.ss.76.2.1965

Engineers Ireland, (2007). Accreditation Criteria for Engineering Education Programmes. Retrieved from http://www.engineersireland.ie/EngineersIreland/media/SiteMedia/services/accr editation/Accreditation-Criteria-for-Engineering-Education-ProgrammesFINAL-amended-Mar-09.pdf 
Fong, P. S. (2003). Knowledge creation in multidisciplinary project teams: An empirical study of the processes and their dynamic interrelationships. International Journal of Project Management, 21(7), 479-486.

Fullan, M. (2001). Leading in a culture of change. San Francisco: Jossey-Bass.

González, C. (2011). Extending research on 'conceptions of teaching': commonalities and differences in recent investigations. Teaching in Higher Education, 16(1), 65-80.

Grbich, C. (2013). Qualitative Data Analysis: An Introduction. London: SAGE.

Guest, G., Bunce, A., \& Johnson, L. (2006). How many interviews are enough? An experiment with data saturation and variability. Field Methods, 18(1), 59-82.

Hobson, J., \& Morrison-Saunders, A. (2013). Reframing teaching relationships: From student-centred to subject-centred learning. Teaching in Higher Education, 18(7), 773-783. doi:10.1080/13562517.2013.836095

Hofmeyer, A., Sheingold, B. H., Klopper, H. C., \& Warland, J. (2015). Leadership in learning and teaching in higher education: Perspectives of academics in nonformal leadership roles. Contemporary Issues in Education Research (CIER), 8(3), 181-192.

Gehrke, S., \& Kezar, A. (2017). The Roles of STEM Faculty Communities of Practice in Institutional and Departmental Reform in Higher Education. American Educational Research Journal, 54(5), 803-833.

Giorgi, A. (2009). The descriptive phenomenological method in psychology: A modified Husserlian approach. Duquesne University Press.

Greenleaf, R. (1977). Servant leadership: A journey into the nature of legitimate power and greatness. New York: Paulist Press.

Ingram, E. L., Litzler, E., Margherio, C., \& Williams, J. M. (2017, June). Board\# 60: Learning to Make Change by Revolutionizing Departments: Initial Team Experiences. In 2017 ASEE Annual Conference \& Exposition.

Irving, P. (2010). A phenomenographic study of introductory physics students: Approaches to their learning and perceptions of their learning environment in a physics problem-based learning environment. Ph.D. dissertation, Dublin Institute of Technology, Ireland.

Isaacowitz, D. M., Wadlinger, H. A., Goren, D., \& Wilson, H. R. (2006). Is there an age-related positivity effect in visual attention? A comparison of two methodologies. Emotion, 6(3), 511.

Järvelä, S., Volet, S., \& Järvenoja, H. (2010). Research on motivation in collaborative learning: Moving beyond the cognitive-situative divide and combining individual and social processes. Educational Psychologist, 45, 15-27.

Kember, D., \& Kwan, K. (2000). Teachers' Approaches to Teaching and Their Relationship to Conceptions of Good Teaching. Instructional Science 28(5): 469-490.

Kerr, C. (2001). The uses of the university. Harvard University Press.

Kezar, A., \& Lester, J. (2011). Enhancing campus capacity for leadership: An examination of grassroots leaders in higher education. Stanford, CA: Stanford University Press.

King, N. (2004). Using templates in the thematic analysis of texts. In C. Cassell \& G. Symon (Eds.). Essential guide to qualitative methods in organizational research (256-270). London: Sage.

Kolmos, A. (2002). Facilitating change to a problem-based model. International Journal for Academic Development, 7(1), 63-74. 
Kouzes, J. M., \& Posner, B. Z. (2007). The leadership challenge ( $2^{\text {nd }}$ ed.). San Francisco: Jossey-Bass.

Kvale, S. (1996). Interviews: An introduction to qualitative research interviewing. London: Sage.

Länsisalmi, H., Peiró, J. M., \& Kivimäki, M. (2004). Grounded Theory in Organizational Research. In C. Cassell \& G. Symon (Eds.). Essential guide to qualitative methods in organizational research (242-255). London: Sage.

Laverty, S. M. (2003). Hermeneutic phenomenology and phenomenology: A comparison of historical and methodological considerations. International Journal of Qualitative Methods, 2(3), 1.

Lenderink, G., Buishand, A., \& Deursen, W. V. (2007). Estimates of future discharges of the river Rhine using two scenario methodologies: direct versus delta approach. Hydrology and Earth System Sciences, 11(3), 1145-1159.

Lynch, K. (1960). The image of the city (Vol. 11). MIT press.

Mason, M. (2010). Sample size and saturation in $\mathrm{PhD}$ studies using qualitative interviews. Forum Qualitative Sozialforschung / Forum: Qualitative Social Research, 11(3).

McKenna, A. F., Yalvac, B., \& Light, G. J. (2009). The role of collaborative reflection on shaping engineering faculty teaching approaches. Journal of Engineering Education, 98(1), 17-26.

Moesby, E. (2002). From pupil to student-a challenge for universities: an example of a PBL study programme. Global Journal of Engineering Education, 6(2), 145152.

Moustakas, C. E. (1994). Phenomenological research methods. Thousand Oaks, California: Sage.

National Science Board, (2007, November 19). Moving forward to improve engineering education. http://www.nsf.gov/pubs/2007/nsb07122/nsb07122.pdf.

Patton, M. Q. (2002). Qualitative Evaluation and Research Methods. (3 ${ }^{\text {rd }}$ ed.). Thousand Oaks, California: Sage.

Pintrich, P. R., \& Zusho, A. (2002). The development of academic self-regulation: The role of cognitive and motivational factors. In A.Wigfield \& J. S. Eccles (Eds.), Development of achievement motivation (pp. 249-284). San Diego, CA: Academic Press.

Perry, J. A. (2014). Changing schools of education through grassroots faculty-led change. Innovative Higher Education, 39(2), 155-168.

Prochaska, J. O., Redding, C. A., \& Evers, K. (2002). The Transtheoretical Model and Stages of Change. In K. Glanz, B.K. Rimer \& F.M. Lewis, (Eds.) Health Behavior and Health Education: Theory, Research, and Practice (3rd Ed.). San Francisco, CA: Jossey-Bass, Inc.

Rogat, T. K., \& Linnenbrink-Garcia, L. (2011). Socially Shared Regulation in collaborative groups: An analysis of the interplay between quality of social regulation and group processes. Cognition and Instruction, 29(4), 375-415.

Rogers, Everett M. (1962). Diffusion of Innovations. Glencoe: Free Press.

Rowley, D. J., Lujan, H. D., \& Dolence, M. G. (1997). Strategic change in colleges and universities: Planning to survive and prosper. San Francisco: Jossey-Bass.

Sanford, N., \& Adelson, J. (1962). The American college. Wiley.

Savin-Baden, M. (2008). Learning Spaces: Creating Opportunities for Knowledge Creation in Academic Life. New York: Open University Press.

Savin-Baden, M., \& Fisher, A. (2002). Negotiating 'Honesties' in the Research Process. British Journal of Occupational Therapy, 65(4). 
Savin-Baden, M., \& Major, C. H. (2013). Qualitative research: The essential guide to theory and practice.

Sedgh, G., Rossier, C., Kaboré, I., Bankole, A., \& Mikulich, M. (2011). Estimating abortion incidence in Burkina Faso using two methodologies. Studies in family planning, 42(3), 147-154.

Seifert, T. L. (1995). Characteristics of ego-and task-oriented students: A comparison of two methodologies. British Journal of Educational Psychology, 65(1), 125-138.

Senge, P. M. (1991). The fifth discipline, the art and practice of the learning organization. Performance Improvement, 30(5), 37-37.

Sergiovanni, T. J. (2007). Leadership as stewardship: "Who's serving who?" The Jossey-Bass Reader on educational leadership (2 ${ }^{\text {nd }}$ ed.). (75-92). San Francisco: John Wiley and Sons.

Smith, J. (1994). Towards reflexive practice: Engaging participants as co-researchers or co-analysts in psychological inquiry, Journal of Community and Applied Social Psychology, (4), 253-260.

Spears, L. (Ed.) (1998). The power of servant-leadership. San Francisco: BerrettKochler Publishers.

Strauss, A., \& Corbin, J. (1994). Grounded theory methodology. In Denezin, N. K. \& Lincoln, Y. S. (Eds.). Handbook of qualitative research. 273-285. Thousand Oaks: Sage Publications.

Sweeney, J. D., Koretsky, M., Bothwell, M. K., Nolen, S. B., \& Montfort, D. (2017, June). Board\# 140: Re-Situating Community and Learning in an Engineering School. In 2017 ASEE Annual Conference \& Exposition.

Trigwell, K., \& Prosser, M. (1996). Changing approaches to teaching: A relational perspective. Studies in Higher Education, 21(3), 275-284.

Tweddell, S., Clark, D., \& Nelson, M. (2016). Team-based learning in pharmacy: The faculty experience. Currents in Pharmacy Teaching and Learning, 8(1), 7-17.

Van Manen, M. (1990). Researching lived experience. New York: State University of New York Press.

Vagle, M. D. (2016). Crafting phenomenological research. Routledge.

Vera, M. I. (1990, September). Effects of divorce groups on individual adjustment: A multiple methodology approach. In Social Work Research and Abstracts (Vol. 26, No. 3, pp. 11-20). Oxford University Press.

Volet, S., Summers, M., \& Thurman, J. (2009). High-level co-regulation in collaborative learning: How does it emerge and how is it sustained? Learning and Instruction, 19, 128-143.

Walker, P. \& Laurence, R. S. (2005). Challenges of greening a decentralized campus: Making the connection to health. In P. F. Bartlett \& G. W. Chase (Eds.), Sustainability on campus: Stories and strategies for change (259-270). Cambridge, MA: MIT Press.

Walsh, L. (2009). A phenomenographic study of introductory physics students: Approaches to problem solving and conceptualisation of knowledge. Ph.D. dissertation, Dublin Institute of Technology, Ireland.

Wicks, D. A., Craft, B. B., Mason, G. N., Gritter, K., \& Bolding, K. (2015). An investigation into the community of inquiry of blended classrooms by a Faculty Learning Community. The Internet and Higher Education, 25, 53-62.

Zimmerman, B. J. (1990). Self-regulating and academic achievement: An overview. Educational Psychologist, 25, 3-17. 



\section{Appendix A - Sample Interview Questions}

Questions used in the 20 November 2012 interview

I'd like to find out about your experience with Group- and Problem-Based Learning in EES. I understand that the focus of the formal learning group (organized by Gavin Duffy with discussion lead by Brian Bowe in 2009) was to talk about facilitating and assessing group-based learning. I'm trying to understand how you experienced the group.

- What was it like, attending these sessions and being part of this group?

- Where you met, in Auinger Street DIT, what was the place like?

- What was the vibe at the peer group meetings?

- Can you tell me about what went on at the meetings?

- Do you have any particularly vivid memories of these meetings?

- What feelings or emotions do you most associate with this group?

- Who came to meetings? How did you feel about them?

- How would you characterize each person's role in the group?

- What were your hopes for this group? Were they met?

- Do you have regrets about this topic?

- Things that happened that you are proud of?

- What did you enjoy about the group? What was frustrating?

I'd also like some background information:

- What prompted your interest in group- and Problem-Based Learning?

- How have you used it in the modules you teach?

- What ideas or techniques did you use? How did you get them?

- Was it hard to implement the ideas? What made this hard?

- Do you have any particularly vivid memories of implementing the approaches?

- What emotions do you associate with group-based PBL?

- Did it make a difference to you that other people were using the approach here, too? How did you know about what they were doing?

- Would you say that the way you think about teaching and learning has changed over time? How? What prompted the changes?

- Have you taken any programs from the LTTC?

- Is there anything else you want to share? What else do you think is important? 


\begin{tabular}{|c|c|c|c|}
\hline $\begin{array}{l}\text { Champion } \\
\text { (Associated } \\
\text { with belief, } \\
\text { persever- } \\
\text { ance, and } \\
\text { focus) }\end{array}$ & $\begin{array}{l}\text { Sage } \\
\text { (Associated } \\
\text { with theory, } \\
\text { research, and } \\
\text { examples) }\end{array}$ & $\begin{array}{l}\text { Institute } \\
\text { (Associated with } \\
\text { ethos, programs, and } \\
\text { policies) }\end{array}$ & $\begin{array}{l}\text { Individuals working } \\
\text { together in groups to } \\
\text { learn and change }\end{array}$ \\
\hline Advocacy & $\begin{array}{l}\text { Role of } \\
\text { research }\end{array}$ & LTTC programs & Who gets involved \\
\hline $\begin{array}{l}\text { - Evangelizing } \\
\text { - Convincing } \\
\text { - Gathering a } \\
\text { small group } \\
\text { - Growing the } \\
\text { group } \\
\text { - Seeing the } \\
\text { benefits } \\
\text { - Group } \\
\text { members } \\
\text { become } \\
\text { advocates } \\
\text { - Drawing } \\
\text { people } \\
\text { toward/ } \\
\text { moving them } \\
\text { along } \\
\text { - Organizer } \\
\text { feeling } \\
\text { empowered } \\
\text { to ask } \\
\text { - Wanting } \\
\text { project as a } \\
\text { driver for the } \\
\text { staff to join } \\
\text { together } \\
\text { - Fellowship } \\
\text { focused } \\
\text { attention on } \\
\text { group- and } \\
\text { problem- } \\
\text { based } \\
\text { learning }\end{array}$ & $\begin{array}{l}\text { - Seeing theory } \\
\text { in action } \\
\text { - Publications } \\
\text { - Conference } \\
\text { attendance } \\
\text { - Technical } \\
\text { research } \\
\text { - Educational } \\
\text { research } \\
\text { - Important to } \\
\text { use } \\
\text { discipline's } \\
\text { words to } \\
\text { convince } \\
\text { others }\end{array}$ & $\begin{array}{l}\text { - Staff members } \\
\text { have taken LTTC } \\
\text { courses voluntarily } \\
\text { or as a requirement } \\
\text { d Lots is happening } \\
\text { on the ground } \\
\text { - Shared } \\
\text { vocabulary } \\
\text { - Those who } \\
\text { participate in the } \\
\text { formal group are } \\
\text { seen to quote } \\
\text { research, justify } \\
\text { and defend ideas } \\
\text { - Policy requirement } \\
\text { for Postgraduate } \\
\text { Certificate in } \\
\text { Learning and } \\
\text { Teaching } \\
\text { d Teaching } \\
\text { Fellowship } \\
\text { - Formal } \\
\text { presentations from } \\
\text { the college Head of } \\
\text { Learning } \\
\text { Development }\end{array}$ & 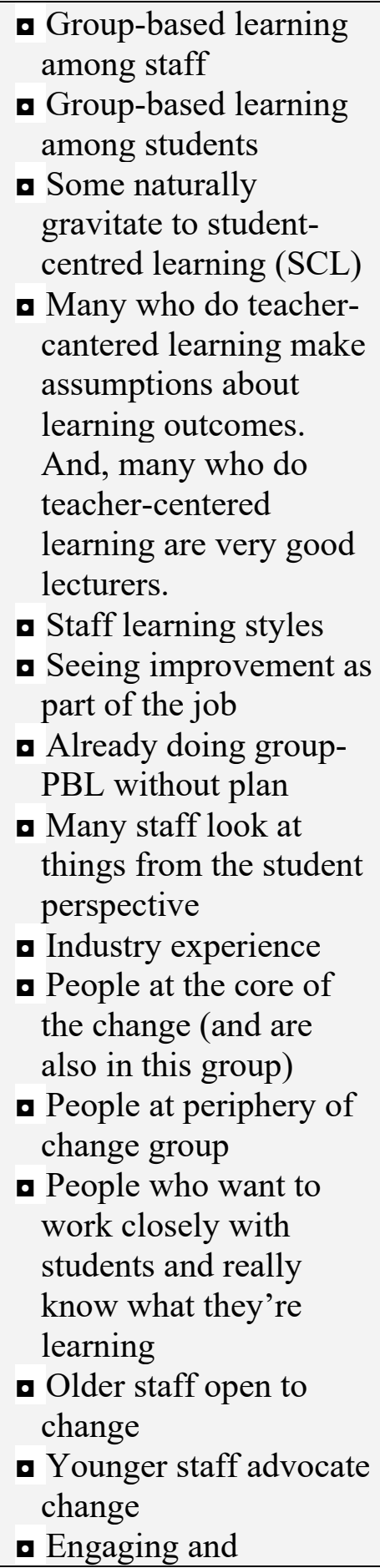 \\
\hline
\end{tabular}




\begin{tabular}{|l|l|l|l|}
\hline & & $\begin{array}{l}\text { stimulating late-career } \\
\text { faculty }\end{array}$ \\
\hline
\end{tabular}

\begin{tabular}{|c|c|c|c|}
\hline Champion & Sage & Institute & $\begin{array}{l}\text { Individuals working } \\
\text { together }\end{array}$ \\
\hline $\begin{array}{l}\text { Ways to } \\
\text { overcome } \\
\text { resistance (at } \\
\text { individual and } \\
\text { department } \\
\text { levels) }\end{array}$ & $\begin{array}{l}\text { Role of } \\
\text { examples }\end{array}$ & Group-think & $\begin{array}{l}\text { Benefits of peer group / } \\
\text { Reasons for being } \\
\text { involved }\end{array}$ \\
\hline $\begin{array}{l}\text { - "Put the } \\
\text { thought in } \\
\text { their minds" } \\
\text { and "Opened } \\
\text { his eyes to } \\
\text { the } \\
\text { possibility" } \\
\text { - Offer } \\
\text { suggestions } \\
\text { - Patience } \\
\text { - Start } \\
\text { innovating } \\
\text { in small } \\
\text { ways and } \\
\text { then } \\
\text { integrate } \\
\text { more } \\
\text { difficult } \\
\text { SCL } \\
\text { approaches } \\
\text { - Advocate so } \\
\text { it becomes } \\
\text { something } \\
\text { others "flow } \\
\text { along" with } \\
\text { - Raising } \\
\text { SCL topic in } \\
\text { Program } \\
\text { Meetings } \\
\text { - [Fellowship } \\
\text { activities, } \\
\text { position } \\
\text { paper, } \\
\text { Fulbright] }\end{array}$ & $\begin{array}{l}\text { - Referencing } \\
\text { the literature } \\
\text { d Physics } \\
\text { d Theory } \\
\text { - Head of } \\
\text { Learning } \\
\text { Development } \\
\text { sharing tips } \\
\text { from } \\
\text { experience } \\
\text { implementing } \\
\text { PBL } \\
\text { elsewhere in } \\
\text { this institution } \\
\text { - Referencing } \\
\text { other } \\
\text { universities } \\
\text { - Critical mass } \\
\text { of early } \\
\text { adopters } \\
\text { d Desire for } \\
\text { more } \\
\text { experiential } \\
\text { learning } \\
\text { approaches in } \\
\text { the } \\
\text { Postgraduate } \\
\text { Certificate } \\
\text { modules in } \\
\text { Learning and } \\
\text { Teaching } \\
\text { - Teaching } \\
\text { observations } \\
\text { - Problems with } \\
\text { follow through }\end{array}$ & $\begin{array}{l}\text { - Shared identity } \\
\text { within this } \\
\text { academic building } \\
\text { - Culture of chatting } \\
\text { (coffee, lunch) } \\
\text { - Peer pressure to } \\
\text { contribute } \\
\text { positively } \\
\text { - People like being } \\
\text { part of this faculty } \\
\text { - People want to get } \\
\text { along } \\
\text { - "It seeps into you" } \\
\text { - Others seeing the } \\
\text { benefits of SCL } \\
\text { and trying to apply } \\
\text { some of it in their } \\
\text { own classes } \\
\text { - The teacher with } \\
\text { the fellowship } \\
\text { working to shift } \\
\text { everyone's } \\
\text { epistemology } \\
\text { - Socratic method } \\
\text { - This institution's } \\
\text { overall ethos (SCL } \\
\text { is an primary ethos } \\
\text { and historically } \\
\text { has been) } \\
\text { - This institution's } \\
\text { ladder system } \\
\text { - This institution's } \\
\text { student } \\
\text { demographic }\end{array}$ & $\begin{array}{l}\text { - Good setting for chats } \\
\text { - Tailored advice } \\
\text { - Tips and strategies } \\
\text { d Enjoyable } \\
\text { - Sounding board and } \\
\text { reigning in } \\
\text { - Confidence } \\
\text { - On-going / constant } \\
\text { discussion } \\
\text { - Sharing experiences } \\
\text { and pooling knowledge } \\
\text { - Healthy debate / } \\
\text { challenging each other } \\
\text { - Encouragement } \\
\text { - Protection } \\
\text { - Supportive } \\
\text { environment } \\
\text { - Positive outcomes or } \\
\text { vibe } \\
\text { - Provided feedback to } \\
\text { staff } \\
\text { - "Cohesiveness of the } \\
\text { group" } \\
\text { - Receptiveness of others } \\
\text { - Learning from the } \\
\text { process } \\
\text { - Learning from the } \\
\text { group } \\
\text { - Learning about theories } \\
\text { - Testing ideas } \\
\text { - Balancing risk with } \\
\text { sense of safety }\end{array}$ \\
\hline
\end{tabular}

\begin{tabular}{|l|l|l|l|}
\hline Champion & Sage & Institute & $\begin{array}{l}\text { Individuals working } \\
\text { together }\end{array}$ \\
\hline What they & Encountering \& & Communicating & Specific topics they \\
\hline
\end{tabular}




\begin{tabular}{|c|c|c|c|}
\hline $\begin{array}{l}\text { want students } \\
\text { to do }\end{array}$ & $\begin{array}{l}\text { understanding } \\
\text { resistance }\end{array}$ & values & discussed \\
\hline $\begin{array}{l}\text { - Think on } \\
\text { their own } \\
\text { - Raise good } \\
\text { questions } \\
\text { - Be } \\
\text { reflective } \\
\text { - Make self- } \\
\text { assessment } \\
\text { - Engage with } \\
\text { the material } \\
\text { - Talk and } \\
\text { share ideas } \\
\text { even on } \\
\text { independent } \\
\text { projects }\end{array}$ & $\begin{array}{l}\text { - Underlying } \\
\text { tensions } \\
\text { - Defensiveness } \\
\text { ("I know how } \\
\text { it works") and } \\
\text { countering/ } \\
\text { arguing against } \\
\text { suggestions } \\
\text { - Seeing people } \\
\text { pretend they } \\
\text { are interested } \\
\text { or getting } \\
\text { "uncomfortable } \\
\text { and leaving" } \\
\text { - Partial buy-in } \\
\text { - Facing } \\
\text { criticism from } \\
\text { others }\end{array}$ & 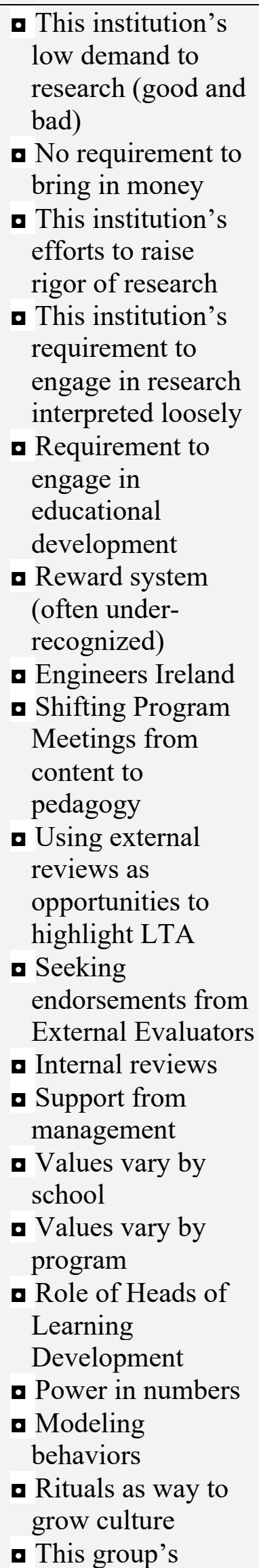 & $\begin{array}{l}\text { - PBL } \\
\text { - GBL facilitation and } \\
\text { assessment } \\
\text { - Problems and what to } \\
\text { do when things go } \\
\text { wrong } \\
\text { - Providing feedback to } \\
\text { students } \\
\text { - Building knowledge or } \\
\text { know-how to facilitate } \\
\text { - Group interaction } \\
\text { - Clickers } \\
\text { - Room format } \\
\text { - Guidance to students } \\
\text { - Posting notes on } \\
\text { Blackboard and then } \\
\text { discussing rather than } \\
\text { lecturing in class } \\
\text { - Letting students build } \\
\text { stuff first year, un- } \\
\text { assessed, for retention } \\
\text { in this group (to get } \\
\text { them engaged and } \\
\text { keep them interested) }\end{array}$ \\
\hline
\end{tabular}




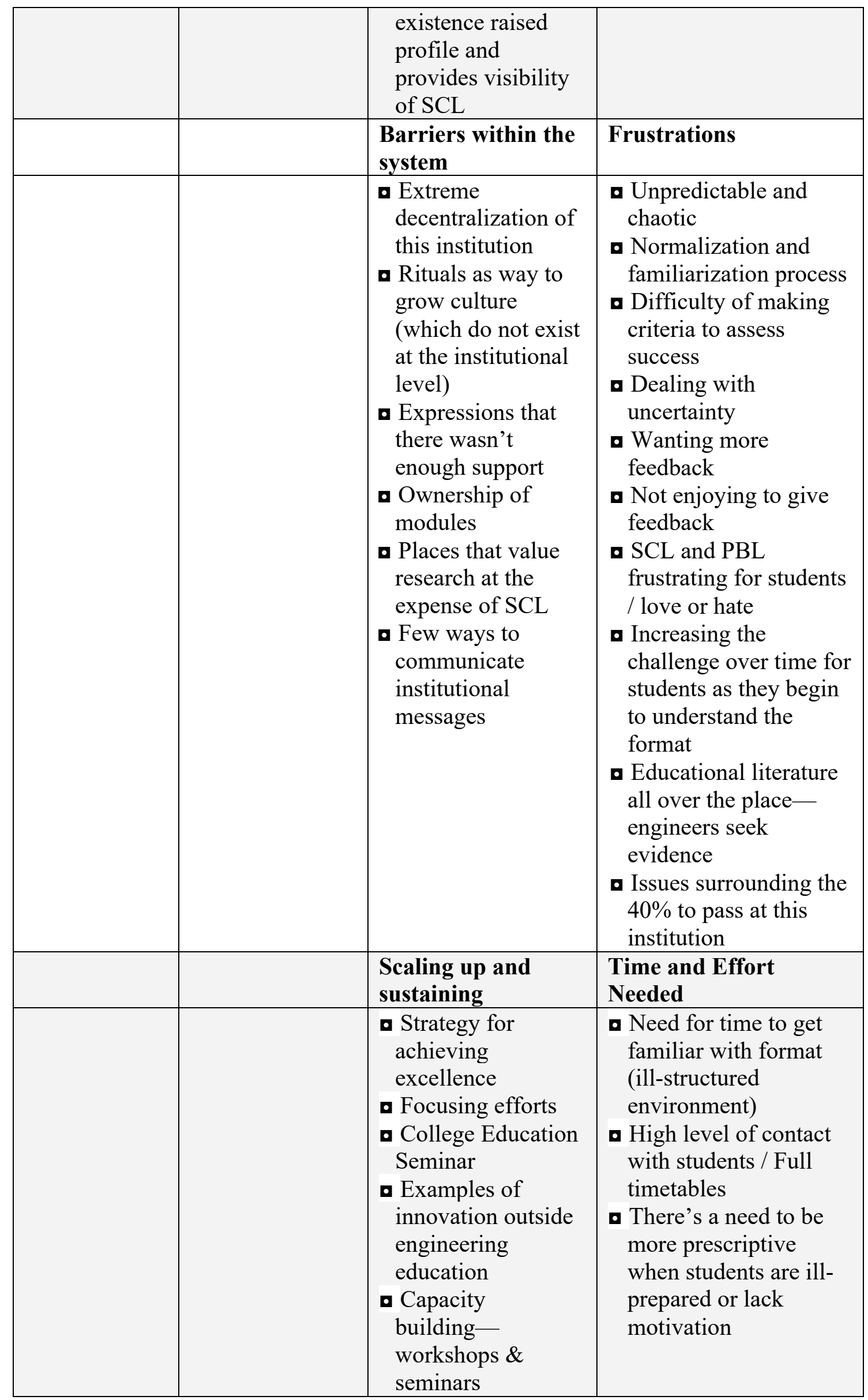




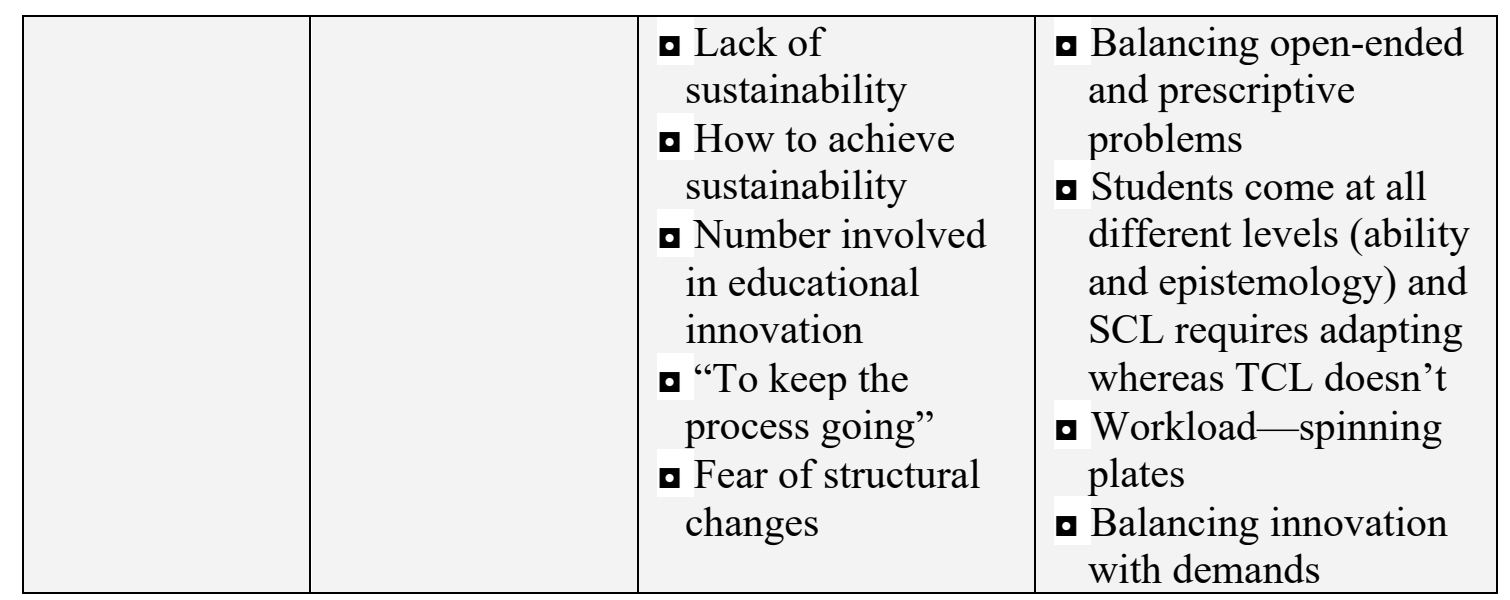

